\title{
Promising Nutritional Fruits Against Cardiovascular Diseases: An Overview of Experimental Evidence and Understanding Their Mechanisms of Action
}

\author{
Nur Zulaikha Azwa Zuraini' \\ Mahendran Sekar (D) \\ Yuan Seng $W^{2,3}$ \\ Siew Hua Gan (D) 4 \\ Srinivasa Reddy Bonam (iD ${ }^{5}$ \\ Nur Najihah Izzati Mat Rani ${ }^{6}$ \\ M Yasmin Begum ${ }^{7}$ \\ Pei Teng Lum' \\ Vetriselvan Subramaniyan ${ }^{8}$ \\ Neeraj Kumar Fuloria ${ }^{9}$ \\ Shivkanya Fuloria ${ }^{9}$
}

'Department of Pharmaceutical Chemistry, Faculty of Pharmacy and Health Sciences, Universiti Kuala Lumpur Royal College of Medicine Perak, Ipoh, Perak, 30450, Malaysia; ${ }^{2}$ Centre for Virus and Vaccine Research, School of Medical and Life Sciences, Sunway University, Selangor, 47500, Malaysia;

${ }^{3}$ Department of Biological Sciences, School

of Medical and Life Sciences, Sunway

University, Selangor, 47500, Malaysia;

${ }^{4}$ School of Pharmacy, Monash University

Malaysia, Bandar Sunway, Selangor Darul

Ehsan, 47500, Malaysia; ${ }^{5}$ Institut National de

la Santé et de la Recherche Médicale, Centre de Recherché des Cordeliers, Sorbonne

Université, Université de Paris, Paris, France; ${ }^{6}$ Faculty of Pharmacy and Health Sciences, Universiti Kuala Lumpur Royal College of Medicine Perak, Ipoh, Perak, 30450, Malaysia; ${ }^{7}$ Department of Pharmaceutics, College of Pharmacy, King Khalid University (KKU), Asir-Abha, 6I42I, Saudi Arabia; ${ }^{8}$ Faculty of Medicine, Bioscience and Nursing, MAHSA University, Selangor, 42610, Malaysia;

${ }^{9}$ Faculty of Pharmacy \& Centre of Excellence for Biomaterials Engineering, AIMST University, Kedah, 08100, Malaysia

Correspondence: Mahendran Sekar Department of Pharmaceutical Chemistry, Faculty of Pharmacy and Health Sciences, Universiti Kuala Lumpur Royal College of

Medicine Perak, Ipoh, Perak, 30450, Malaysia

Tel $+6016-3346653$

Fax $+605-2536634$

Email mahendransekar@unikl.edu.my

\begin{abstract}
Cardiovascular diseases (CVDs) are one of the leading causes of morbidity and mortality in both developed and developing countries, affecting millions of individuals each year. Despite the fact that successful therapeutic drugs for the management and treatment of CVDs are available on the market, nutritional fruits appear to offer the greatest benefits to the heart and have been proved to alleviate CVDs. Experimental studies have also demonstrated that nutritional fruits have potential protective effects against CVDs. The aim of the review was to provide a comprehensive summary of scientific evidence on the effect of 10 of the most commonly available nutritional fruits reported against CVDs and describe the associated mechanisms of action. Relevant literatures were searched and collected from several scientific databases including PubMed, ScienceDirect, Google Scholar and Scopus. In the context of CVDs, 10 commonly consumed nutritious fruits including apple, avocado, grapes, mango, orange, kiwi, pomegranate, papaya, pineapple, and watermelon were analysed and addressed. The cardioprotective mechanisms of the 10 nutritional fruits were also compiled and highlighted. Overall, the present review found that the nutritious fruits and their constituents have significant benefits for the management and treatment of CVDs such as myocardial infarction, hypertension, peripheral artery disease, coronary artery disease, cardiomyopathies, dyslipidemias, ischemic stroke, aortic aneurysm, atherosclerosis, cardiac hypertrophy and heart failure, diabetic cardiovascular complications, drug-induced cardiotoxicity and cardiomyopathy. Among the 10 nutritional fruits, pomegranate and grapes have been well explored, and the mechanisms of action are well documented against CVDs. All of the nutritional fruits mentioned are edible and readily accessible on the market. Consuming these fruits, which may contain varying amounts of active constituents depending on the food source and season, the development of nutritious fruits-based health supplements would be more realistic for consistent CVD protection.
\end{abstract}

Keywords: nutritional fruits, cardiovascular diseases, heart disease, antioxidant, hypertension, nutraceuticals

\section{Introduction}

In recent years, cardiovascular diseases (CVDs) have contributed to millions of cases worldwide and is becoming one of the leading causes of morbidity and mortality in both developed and poor countries. ${ }^{1}$ Generally, CVDs encompass blood vessel and heart diseases, cerebrovascular disease (stroke), coronary heart disease (heart attacks), raised blood pressure (hypertension), rheumatic heart disease, heart failure, peripheral artery disease and congenital heart disease. CVDs are mainly contributed by sedentary 


\section{Graphical Abstract}

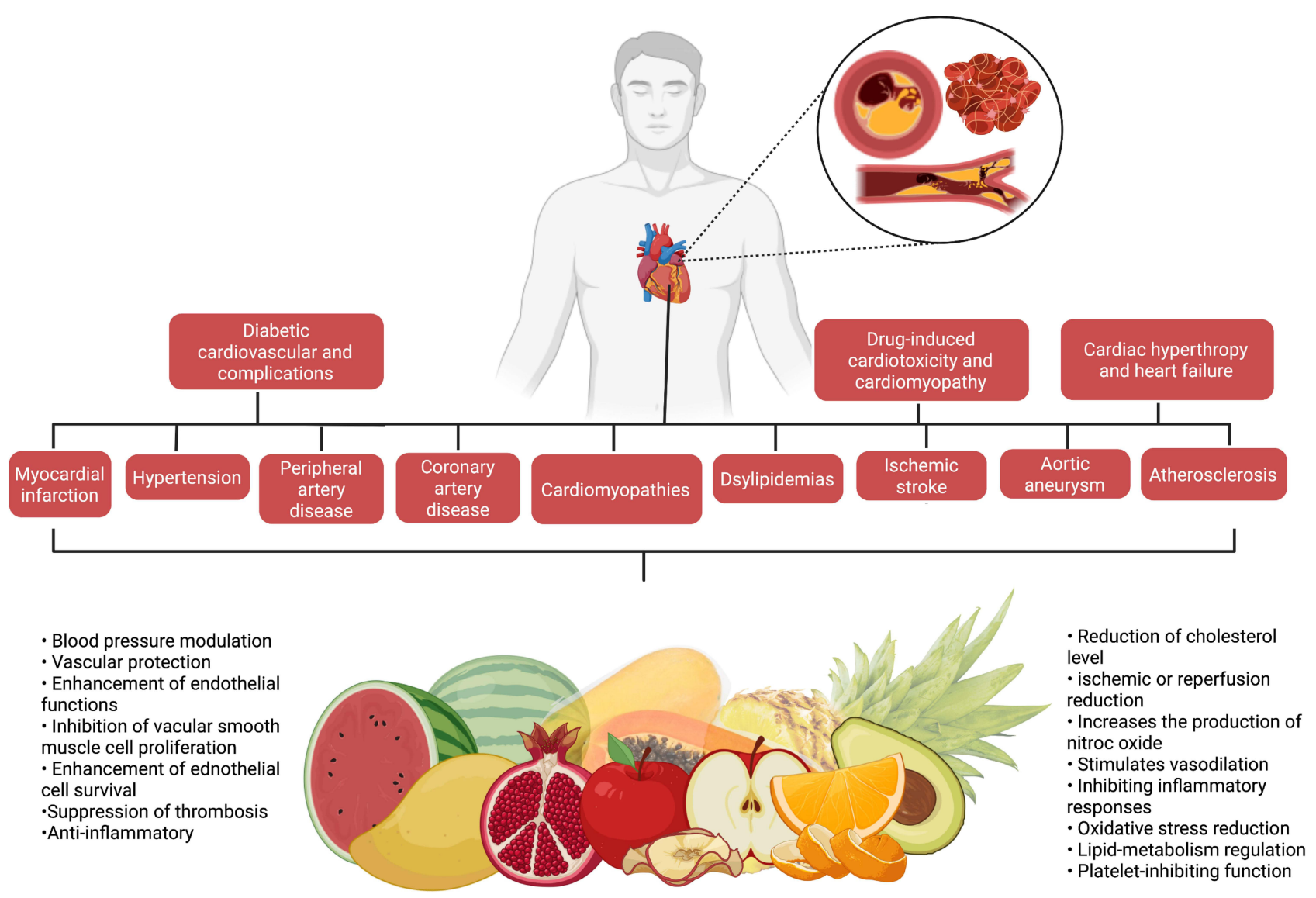

lifestyles, such as lack of physical activity, cigarette smoking and unhealthy eating habits, causing increasing prevalence across the world. ${ }^{2}$

The heart is a muscular pump that collects blood from the body's tissues and pumps it into the lungs, as well as collecting blood from the lungs and pumping it to the rest of the body's tissues. The human heart is supported by the superior surface of the diaphragm and is located in the protective thorax, posterior to the sternum and costal cartilages. ${ }^{3}$ The heart is a thick and muscular organ of the vascular system contracts in a rhythmic manner. It has four chambers: a right atrium, a left atrium, and right and left ventricles (Figure 1). Left and right chambers are not connected directly, but have one common wall called septum, which is the midline component of each chamber. There will be changes in blood pressure within the chambers as the valves open and close. The pressure in the ventricles increases higher than in the atria, and the valves close to prevent blood from flowing backward. The chordae tendineae, which extend from the inferior surface of the valve cusps to the ventricle wall, restrict the valves from opening upwards. ${ }^{4}$

Cardiovascular system involved vasculature and heart. The cardiac system generates heartbeats based on autonomic nerve conditions, and the vascular system transports blood throughout the body via a vascular network. Both systems interact with one another in the body. ${ }^{5}$ The cardiac vasculature and heart tissue can be affected by radiation exposure. The vasculature shows a typical blood vessel with endothelium and smooth muscle cells (SMCs), which may play a role in pathophysiological processes following radiation exposure. SMCs are not found in capillaries, however endothelium damage can influence them. This can lead to coronary artery disease (CAD), also known as ischemic heart disease (IHD), stroke, and other vascular diseases, as well as congestive heart failure (CHF). ${ }^{6}$ 


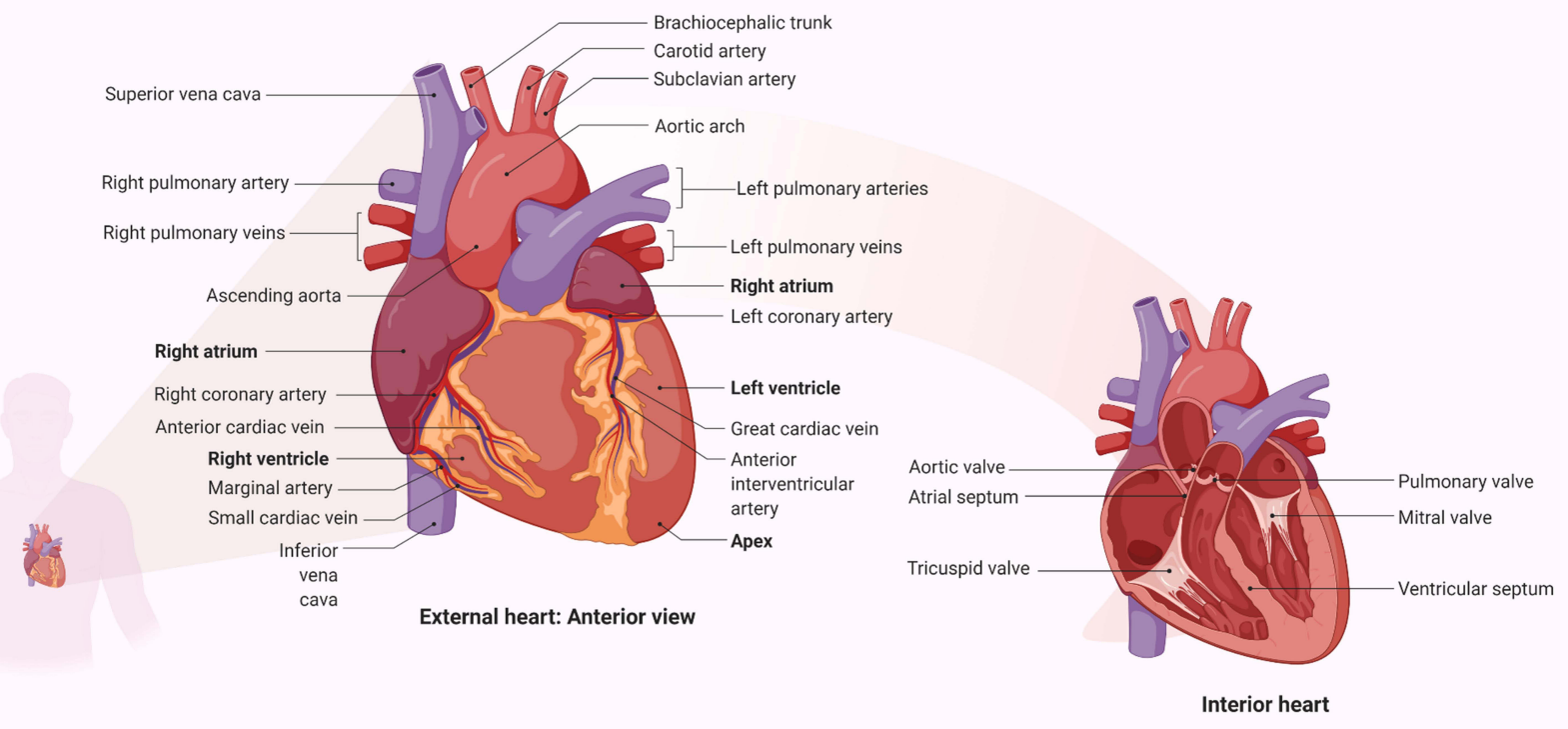

Figure I Parts of the cardiovascular system and their functions. The upper two (or atria) chambers operate mainly as chambers for collection, while the lower two chambers (ventricles) are considerably stronger and are used to provide blood. The right atrium and ventricle are responsible for collecting blood from the body and pumping it to the lungs. Blood is collected from the lungs and pumped throughout the body by the left atrium and ventricle. The heart has a one-way flow of blood, which is maintained by a series of four valves. The tricuspid and bicuspid atrioventricular valves allow blood to pass only from the atria to the ventricles. Only blood from the ventricles can flow out of the heart through the semilunar valves (pulmonary and semilunar). ${ }^{3}$ In other side, it should be noted that in addition to pumping oxygen-rich blood into body tissues, the blood also circulates many other important substances for oxygen exchange for carbon dioxide. As example, digestive nutrients are collected from the small intestine and pumped into all the cells in the body by the circulatory system. The circulatory system transports waste materials from cells into the kidneys, extracted and transmitted into the bladder. An important function of the heart in this matter is the pumping of interstitial blood fluid into the extracellular space. The circulatory system then returns excess interstitial fluid through the lymphatic system. ${ }^{3}$ The heart is a rhythmic electromechanical pump as its performance is dependent on the formation and propagation of action potentials, followed by relaxation and a period of refractoriness before the next impulse is created. The inward of $\mathrm{Na}^{+}$current and outward of $\mathrm{K}^{+}$current carrying ion channels are sequentially activated and inactivated in myocardial action potentials. Due to variances in $\mathrm{Na}^{+}$, Ca ${ }^{2+}$, and $\mathrm{K}^{+}$channel expression in different parts of the heart, action potential waveforms are diverse, and these differences contribute to the normal, unidirectional transmission of activity and the formation of normal cardiac rhythms. ${ }^{154}$

Biological factors such as lower levels of HDL cholesterol and high levels of LDL cholesterol can cause an increased trend in the congenital heart disease (CHD) risk. The rise in triglyceride levels also increases the risk of CVDs. The study by Rehan et $\mathrm{al}^{7}$ found that abnormal blood lipid levels are the largest and most important factor that can cause myocardial infarction (MI). Reducing the intake of saturated fat and careful monitoring and treatment of cholesterol can reduce the risk of getting CVDs. The high blood pressure can also be the factor that kills 6 million people each year and represents $13.5 \%$ of the world's deaths annually. Moreover,few studies reported that decreasing physical activity levels can be the factor affecting the cardiovascular system. These can be supported by a study carried out in China that estimates that adults have much less movement while working with better transportation and high-technology house appliance. Besides, a decline of $32 \%$ on the average weekly physical exercise has been observed in the same study. Sitting behaviours have also dramatically increased. This issue has been taken action by specialists in health and researchers proposed physical activity to reduce the global burden of chronic diseases, especially CVDs. ${ }^{8}$ Ultimately, remaining physically inactive results in obesity, which can significantly enhance the risk of CVDs. ${ }^{9}$

Diet can also affect the cardiovascular system. In this matter, Amine et $\mathrm{al}^{10}$ conducted an epidemiological study on the relationship between CVDs and diets. Although individual food group intake has given big impacts on CVDs based on the nutritional research, various dietary patterns and their impact on CVDs risk were investigated in recent years. As example, reducing the intake of saturated fat, keeping the intake of fish, linoleic acid and potassium, taking the whole grains, seeds, nuts and drinks, can help in declining the risk of developing CVDs. Stress, anxiety, depression, coldness and the absence of peer assistance can also affect the cardiovascular system. Psychological factors have promoted some unhealthy behaviours, such as smoking, frequent consumption of alcohol, physical inactivity, poor diet and medicines that can contribute to indirect growth in the risk of CVDs. ${ }^{11}$ Thus, preventive measures are needed in both early 
Table I List of CVDs and Their Pathophysiology

\begin{tabular}{|c|c|c|c|}
\hline Disorder/Disease & Causative Factor & Pathophysiology & Reference \\
\hline $\begin{array}{l}\text { Cerebrovascular } \\
\text { disease (stroke) }\end{array}$ & Cerebral haemorrhage and ischemia & $\begin{array}{l}\text { The narrowing of veins due to atherosclerosis } \\
\text { causes thrombosis, which reduces blood flow. } \\
\text { Plaque build-up gradually narrows the vascular } \\
\text { chamber, causing clots and thrombotic stroke. } \\
\text { Haemorrhagic stroke is the most common type } \\
\text { of stroke, accounting for } 10-15 \% \text { of all strokes } \\
\text { and having a high fatality rate. Blood vessels } \\
\text { break due to tension in the tissue and internal } \\
\text { harm in this illness. It has harmful effects on the } \\
\text { vascular system, which can lead to infarction. }\end{array}$ & $\begin{array}{l}\text { Kuriakose and } \\
\text { Xiao, }{ }^{144} \text { Markus }^{145}\end{array}$ \\
\hline Heart attacks & Smoking and coronary artery disease (CAD) & $\begin{array}{l}\text { Plaque, a waxy substance that accumulates } \\
\text { inside the lining of major coronary arteries, can } \\
\text { block blood flow in the heart's large arteries } \\
\text { partially or entirely. An illness or injury that } \\
\text { changes the way the heart's arteries function } \\
\text { might cause some types of this illness. Ischemia } \\
\text { and subsequent myocardial infarction occur } \\
\text { when a cardiac artery is fully blocked, resulting } \\
\text { in a lack of oxygen and nutrients. }\end{array}$ & $\begin{array}{l}\text { Libby and } \\
\text { Theroux }{ }^{146}\end{array}$ \\
\hline $\begin{array}{l}\text { Raised blood } \\
\text { pressure } \\
\text { (hypertension) }\end{array}$ & $\begin{array}{l}\text { Elevated serum cholesterol, salt intake, glucose } \\
\text { intolerance, obesity, and stress. }\end{array}$ & $\begin{array}{l}\text { Systemic vascular resistance, vascular stiffness, } \\
\text { and vascular response to stimuli are all } \\
\text { elevated. }\end{array}$ & Foëx and Sear ${ }^{147}$ \\
\hline $\begin{array}{l}\text { Rheumatic heart } \\
\text { disease }\end{array}$ & $\begin{array}{l}\text { Congenital heart disease (CHD), mitral valve } \\
\text { prolapse (MVP), acquired valve disease and } \\
\text { changes in the valve of heart. }\end{array}$ & $\begin{array}{l}\text { Cross-activation of antibodies and/or T cells } \\
\text { directed against human proteins is caused by } \\
\text { structural similarities between the infectious } \\
\text { agent and human proteins. This cross-reactive } \\
\text { immune response in acute rheumatic fever } \\
\text { (ARF) causes rheumatic fever-like symptoms. It } \\
\text { can affect many connective tissues in the heart } \\
\text { that leads to inflammation. }\end{array}$ & $\begin{array}{l}\text { Carapetis et al, }{ }^{148} \\
\text { Cunningham, }{ }^{149} \\
\text { Kumar and } \\
\text { Tandon }^{150}\end{array}$ \\
\hline Heart failure & $\begin{array}{l}\text { Valvular heart disease, hypertension, viral } \\
\text { myocarditis, atrial fibrillation, alcohol, coronary } \\
\text { artery disease, arrhythmias and pericardial disease. }\end{array}$ & $\begin{array}{l}\text { This is characterized by the heart's inability to } \\
\text { pump enough blood into the circulation during } \\
\text { systole, which is known as left ventricular } \\
\text { systolic dysfunction. The most common test } \\
\text { for left ventricular systolic function is } \\
\text { echocardiography, with an ejection fraction of } \\
40 \% \text { suggesting compromised left ventricular } \\
\text { systolic function. Furthermore, heart failure } \\
\text { with preserved left ventricular ejection fraction } \\
\text { (PLVEF) or "diastolic" heart failure can arise in } \\
\text { patients with adequate left ventricular systolic } \\
\text { function who require higher filling pressures to } \\
\text { achieve a normal end-diastolic volume of the } \\
\text { left ventricle. }\end{array}$ & $\begin{array}{l}\text { Mosterd and } \\
\text { Hoes }^{151}\end{array}$ \\
\hline
\end{tabular}

(Continued) 
Table I (Continued).

\begin{tabular}{|l|l|l|l|}
\hline Disorder/Disease & Causative Factor & Pathophysiology & Reference \\
\hline $\begin{array}{l}\text { Congenital heart } \\
\text { disease }\end{array}$ & $\begin{array}{l}\text { Maternal rubella infection, maternal systemic lupus } \\
\text { erythematosus (SLE), maternal diabetes, Down's } \\
\text { Syndrome and Turner's Syndrome. }\end{array}$ & $\begin{array}{l}\text { This mechanism of damage results in } \\
\text { pulmonary vascular endothelial damage and the } \\
\text { destruction of endothelial barrier function. This } \\
\text { activates vascular elastase and matrix } \\
\text { metalloproteinases, causing extracellular matrix } \\
\text { degradation and fibroblast growth factor (FGF) } \\
\text { and transforming growth factor } \beta \text { I (TGF- } \beta \text { I) } \\
\text { release. Smooth muscle cell hypertrophy and } \\
\text { proliferation, as well as the creation of neo- } \\
\text { intima, are all caused by such release. Overall } \\
\text { incidence increases asymmetrical septal } \\
\text { hypertrophy. }\end{array}$ & $\begin{array}{l}\text { Pascall and } \\
\text { Tulloh }\end{array}$ \\
& & \\
\hline
\end{tabular}

childhood and medium age population to control and manage heart disease better. Table 1 summarizes the list of CVDs and their pathophysiology.

Plant-based diets, such as fruits, have thus far displayed positive effects in both the prevention and control of CVDs. ${ }^{12}$ Observational studies and clinical research have shown that fruit consumption lowers the risk of CVDs, which is contributed by the presence of bioactive compounds. ${ }^{12}$ Willett ${ }^{13}$ also stated that an appropriate dietary approach having more plantbased foods played a key role in preventing chronic diseases, including heart disease. It has been reported that a proper diet can keep human healthy. ${ }^{14,15}$ Women with Type 2 diabetes are more likely to be assigned a lower CVD risk category and to receive lifestyle counseling as well as less intensive CVD therapy compared with men. ${ }^{16}$ However, CVD continues to be the primary cause of morbidity and mortality in women around the world. ${ }^{17}$ Fruits and vegetables are considered a heart-healthy diet that can help avoid heart disease. According to Mattioli et al, ${ }^{18}$ women and especially pre-menopausal women who ate a lot of fruits and vegetables had a lower risk of developing preclinical peripheral atherosclerosis. In fact, CVDs can be avoided by consuming a diet high in fruits, vegetables and low-fat dairy products, as well as focusing on a diet low in fat, red meat, sweets and sugary beverages. Additionally, soda and sodium chloride consumption should be reduced, and potassium, calcium, magnesium, vitamin $\mathrm{C}$ and omega-3 fatty acids increased. Of note, plant-food bioactive molecules, such as polyphenolic compounds, peptides, oligosaccharides, vitamins and fatty acids, are examples of diverse chemical structures with cardioprotective properties..$^{19,20}$

This review focuses on the CVDs protective potentials of 10 commonly consumed nutritional fruits, including apple, avocado, grape, mango, orange, kiwifruit, pomegranate, papaya, pineapple and watermelon (Figure 2), to increase public awareness regarding the importance of nutritious fruits' consumption, especially for those with cardiovascular risk factors, with the aim in determining their effectiveness in CVDs prevention. This review will also provide recommendations for reducing CVDs to national and international government bodies, health professionals and people in the community.

\section{Methods}

Relevant literature was searched from several reliable scientific databases, including PubMed, ScienceDirect, Google Scholar and Scopus website to complete this review. Search strategy was performed using several keywords: "Apple" or "Malus domestica", "Avocado" or "Persea americana", "Grapes" or "Vitis vinifera", "Mango" or "Mangifera indica", "Orange" or "Citrus sinensis", "Kiwi" or "Actinidia deliciosa", "Pomegranate" or "Punica granatum", "Papaya" or "Carica papaya", "Pineapple" or "Ananas comosus", "Watermelon" or "Citrullus lanatus", in combination with "Heart Disease", "Cardiovascular Disease", "Heart Failure" or "Heart Injury". Following the completion of the screening, the obtained information was summarised and included in the current review.

\section{Nutritional Fruits Conferring Protection Against CVDs in Experimental Models}

\section{Apple (Malus domestica)}

Apples are among the most devoured nutritional fruit belongs to the family of Rosaceae. Apple trees are the 

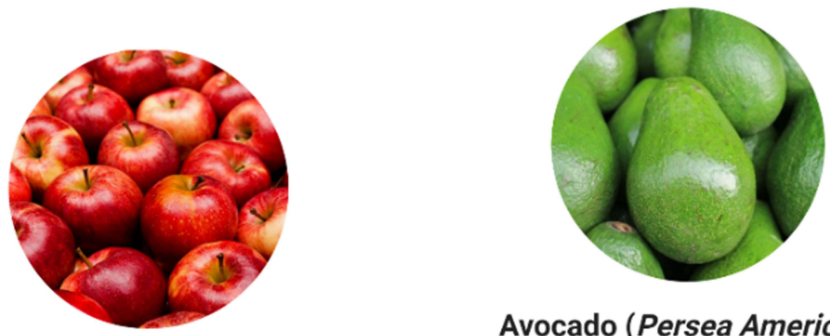

Avocado (Persea Americana)

Apple (Malus domestica)
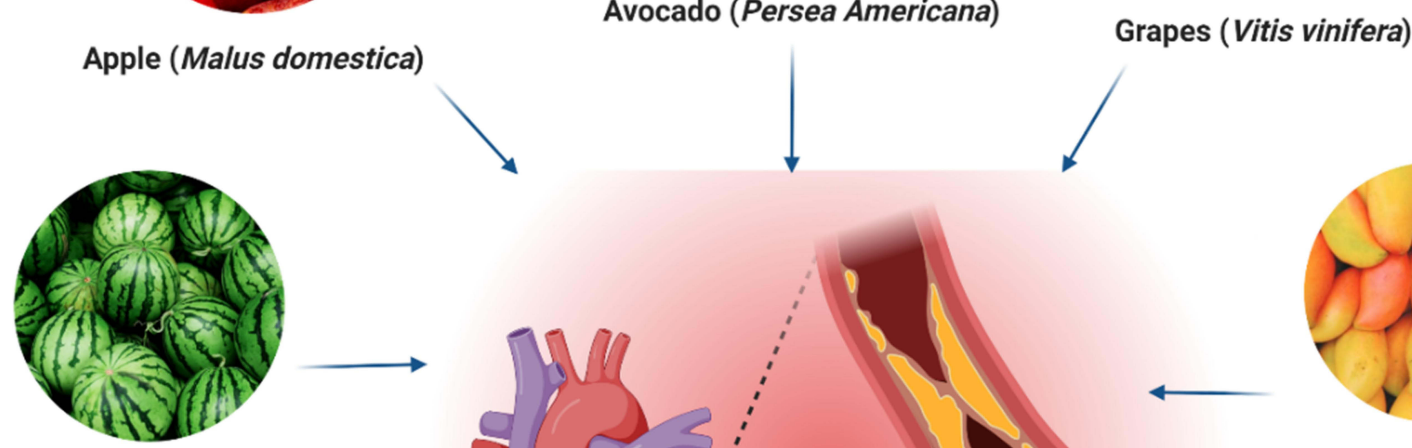

Watermelon (Citrullus lanatus)

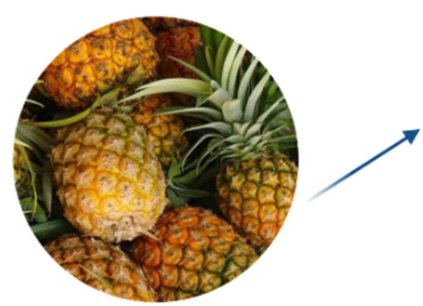

Pineapple (Ananas comosus)

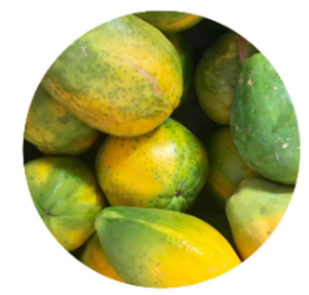

Papaya (Carica papaya)
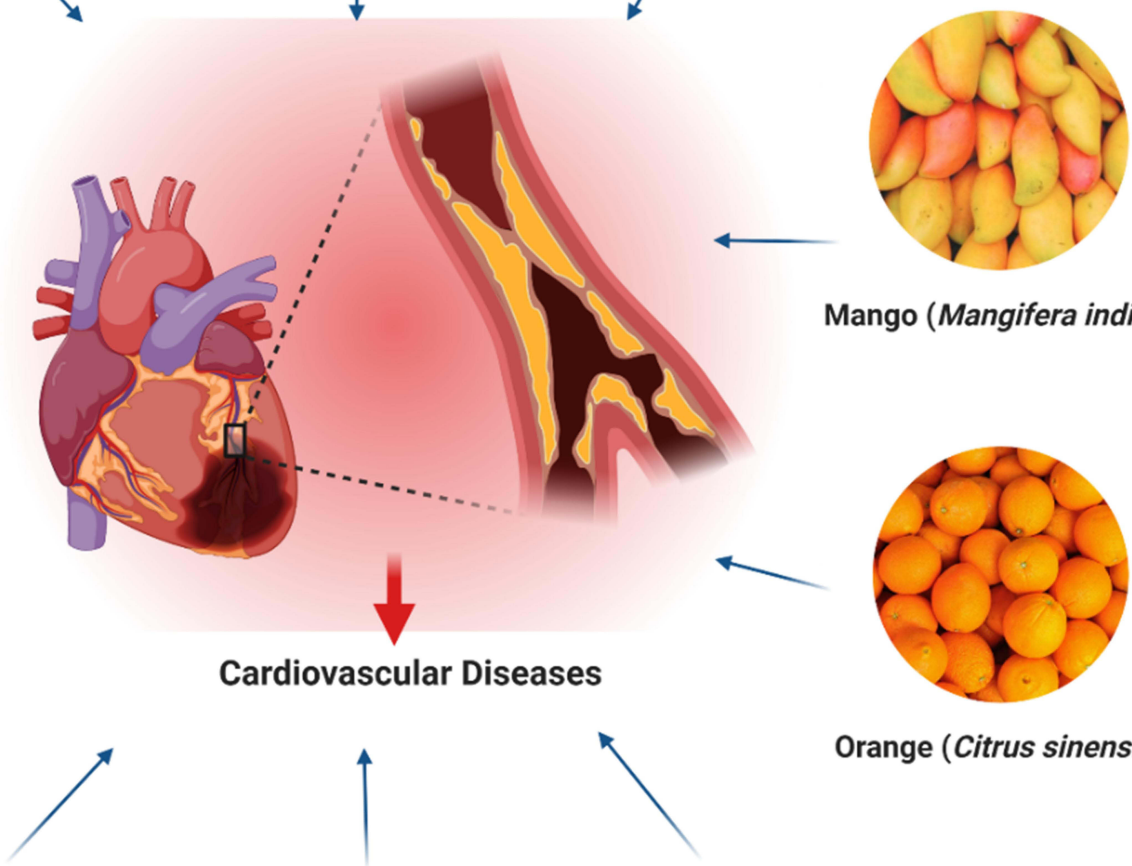

Mango (Mangifera indica)

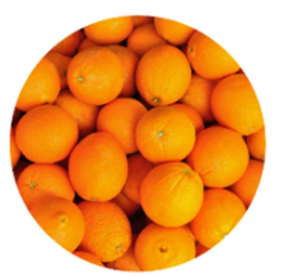

Orange (Citrus sinensis)
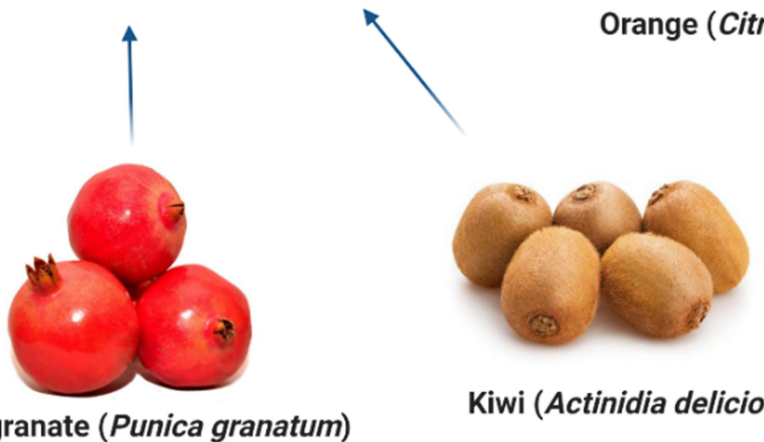

Kiwi (Actinidia deliciosa)

Pomegranate (Punica granatum)

Figure 2 Nutritional fruits conferring protection against CVDs.

most commonly grown species in the Malus genus and are grown worldwide. Sandoval-Ramírez et al $^{21}$ established that the admission of the entire apple was related to a decreased danger of CVDs' mortality, ischemic heart disease mortality, stroke mortality and serious stomach aortic calcification, with lower C-reactive protein (CRP) level in body. This claim is because apple could decrease cholesterol level, low-density lipoprotein cholesterol (LDL-c), pulse rate, systolic blood pressure and perceptibly diminished CRP, as well as helping with increasing high-density lipoprotein (HDL) level and endothelial function. Besides, the results also demonstrated that apples were able to reduce plasma lipids, particularly total cholesterol (TC) values but depending on the amount consumed (Figure 3). These findings suggested that if we consume at least one whole apple (100-150 g) per day in order to significantly reduce all-cause mortality risk associated with CVDs. $^{22}$

Moreover, a study by Bondonno et $\mathrm{al}^{23}$ demonstrated that the cardioprotective effects of apples are mainly due to the presence of flavonoids that are highly abundant in the apple skin. An investigation with the observational 
Bioactive compounds present in apple (Malus domestica)

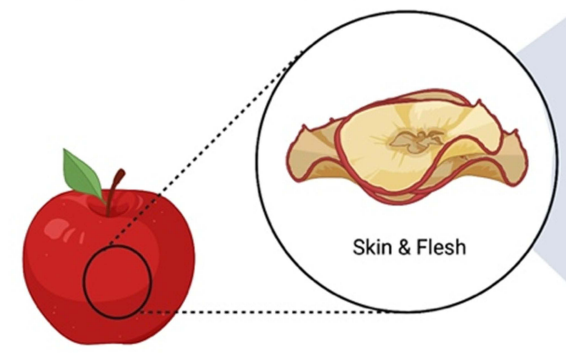

Cardioprotective effects of Malus domestica

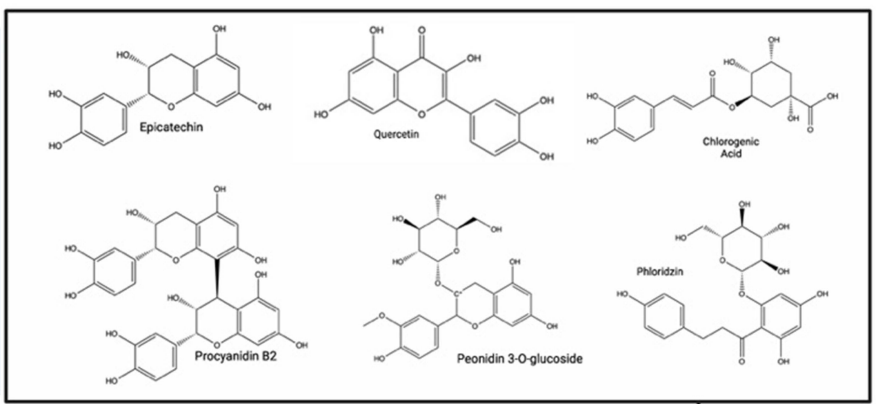

1

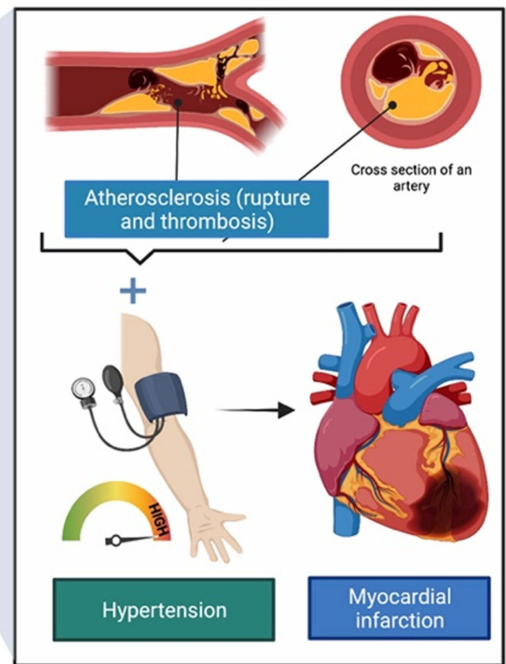

Figure 3 Bioactive compounds present in apple (Malus domestica) and its cardioprotective effects. Apple polyphenols are abundant in the flesh and peel of the fruit and contribute to the improvement of blood pressure, endothelial function, and arterial stiffness in those at increased risk of cardiovascular disease (CVDs). A healthy heart permits blood to be pumped out via a network of blood channels known as arteries. The left side of the heart takes oxygen-rich blood from the lungs and pumps it out via a big artery called the aorta, while deoxygenated blood returns to the heart via blood vessels called veins. However, atherosclerosis, a buildup of plaque inside the arterial walls, may cause the arteries to narrow, making blood circulation more difficult. The combination of hypertension and atherosclerosis will eventually result in more significant issues such as myocardial infection, more often referred to as a heart attack.

study was conducted among 30 volunteers in 4 weeks to determine if consuming apple with its skin could improve endothelial function, blood pressure and arterial stiffness in individuals at higher risk for CVDs. A comparison was made between the intake of apple with skin (flavonoid-rich content) and only apple flesh (less flavonoid content). The outcome met the hypothesis that an increase in apple consumption could lower the risk of CVDs, either acute or chronic heart disease, which is mediated by the protective effect of apple skin. Scientific research has shown that apples are rich in polyphenols and pectin, which are known to be bioactive elements. However, the intake of apple juice in a clear form will not have any therapeutic effects on CVDs. ${ }^{24}$ Ravn-Haren et $\mathrm{al}^{25}$ reported that apple contains polyphenols and pectin but that the clear form of apple juice lacks pectin and other cell wall components. Since the fibre components in apples are essential for healthy humans to lower cholesterol, clear apple juice might not be a good substitute for the whole fruit in nutritional recommendations.

In addition to CVDs, polyphenols in apples have other therapeutic benefits, such as preventing degenerative diseases. Apple polyphenols reduce the risk of CVDs by having a beneficial effect on the intestinal microflora. ${ }^{26}$ Besides, multiple studies have reported that the polyphenol percentage in the overall phenolic and flavonoid content of apple peel extract is substantially higher than apple fleshes. Interestingly, Tian et $\mathrm{al}^{27}$ showed that mice administered with $250 \mathrm{mg} / \mathrm{kg}$ apple peel and apple flesh extracts for 28 days had lower blood pressure, ${ }^{28}$ improved endothelial function, improved lipid homeostasis and reduced insulin resistance. The results further indicated that apple peel extract possessed greater cardioprotective effects against atherosclerosis in mice than apple flesh extract. ${ }^{27}$ Furthermore, it was shown that the presence of major compounds in apple varieties, such as catechin, 
epicatechin and procyanidin B1 polyphenols, demonstrated a cardiovascular protective effect on rats by reducing blood cholesterol levels. ${ }^{29}$ Another study found that apple peel reduced glycemia, TC, HDL-cholesterol (HDLc), LDL-c, triglycerides (TG), ureic nitrogen, insulin, and asymmetric dimethylarginine in CF-1 mice with metabolic syndrome, reduced cholesterol accumulation region, and reverted atherogenesis progression in $\mathrm{ApoE}^{-/-}$mice. $^{30}$ Besides, apple peel extracts also contain flavonoids that have been beneficial in treating hypertension and other CVDs. ${ }^{31}$ Therefore, daily intake of apple is one of the initiative steps to prevent any CVDs mortality. It is also advisable for people, especially patients with CVDs, to increase the intake of the whole apple, as it can improve TC, reduce blood pressure, LDL levels, as well as prevent inflammation. Besides, it is encouraged to eat an apple together with its skin, as it facilitates high chances of getting cardioprotection.

\section{Avocado (Persea americana)}

Persea americana belongs to the family of Lauraceae, which is originated in south-central Mexico. Avocado is a large berry with a single large seed that is the fruit of the $P$. americana tree. Few studies have evaluated the effects of avocado intake on lipid and cholesterol levels that are implicated in the development of heart diseases. Avocado fruit intake not only decreases serum TC, LDL-c and TG concentrations but also increases serum HDL-c concentrations, with significant heterogeneity (Figure 4). ${ }^{32}$

In a rat model of sucrose-induced metabolic changes, cardiovascular risk profile markers were assessed after avocado oil treatment, ${ }^{33}$ The avocado oil treatment significantly decreased TG, very low-density lipoprotein (VLDL) and LDL levels but had no effect on HDL levels. It also markedly reduced high-sensitivity CRP levels, which is an inflammatory marker. The findings revealed that consuming avocado oil can reduce inflammatory processes and positively change biomarkers linked to metabolic syndrome progression. ${ }^{33}$ A natural remedy has been used as part of complementary therapies in cardiac disorders. For instance, an investigation has evaluated the effect of acute avocado pulp intake on cardiovascular and autonomic recovery after moderate exercise. ${ }^{34}$ Besides, avocado seeds have found to contain phenolic acids and flavonoids, which are well known to have protective activity against cardiovascular health. ${ }^{35}$ Some earlier studies have also shown that avocado oil and avocado pulp extracts have beneficial effects on improving cardiovascular measures in rats. The intake of avocado oil has claimed to reduce TG, CRP, LDL and VLDL levels in rats. Besides, avocado pulp is used as anti-platelet and anti-thrombotic agents, while the avocado fruit itself is recommended to be taken one per day in order to achieve good improvement of cholesterol levels. ${ }^{36}$

The treatment of methanolic seed extracts of avocado $(200,400,800$ and $1600 \mathrm{mg} / \mathrm{kg} /$ day for 4 weeks) in mice prolonged prothrombin time (PT) and activated partial thromboplastin time (APTT) in a dose-dependent manner. ${ }^{37}$ According to the findings, this impact may be attributed to avocado seeds' high potassium content, which is recommended in anticoagulant therapy. ${ }^{37}$ Therefore, avocado pulp was studied for its in vitro and in vivo antiplatelet and antithrombotic properties. The results showed that antiplatelet activity was contributed by the presence of persenone-C, the most active antiplatelet acetogenin and persenone-A. ${ }^{38}$ Increased coagulation times and reduced thrombus formation were seen as the protective effects against arterial thrombosis with the treatment of persenone-A $(25 \mathrm{mg} / \mathrm{kg})$ in-vivo thrombosis model. Avocado inhibited platelet aggregation due to the presence of acetogenin compounds, which these compounds had a possible anti-thrombotic activity and were effective in ischaemic diseases. ${ }^{38}$ Apart from these, Gouegni and Abubakar ${ }^{39}$ investigated the phytochemical, toxicological, biochemical and haematological profiles of avocado fruit extracts. The extract treatment reduced TC, VLDL and LDL, while HDL levels increased. The study further found that PT and APTT were reduced by kaolin in the fruit extracts. Because of its preventive and possibly curative properties, the avocado fruit extracts may be considered a potential inhibitor of CVDs. Vitamin K has often been considered essential for the synthesis of prothrombin and other clotting factors. The crude extract of P. americana also had high vitamin $\mathrm{K}$ content; thus, they can play a role in regulating blood clotting time. ${ }^{39}$ Furthermore, avocado seeds improved hypercholesterolemia and assisted in preventing and treating hypertension, inflammatory disorders, and diabetes. ${ }^{40}$ All the above findings indicated that avocado fruit has similar cardiovascular effects with its pulp and seed oil. Taken together, avocado fruit could improve cardiovascular recovery after exercise by preventing the risk of cardiovascular problem. It has proved to control cholesterol levels and treat CVDs.

\section{Grapes (Vitis vinifera)}

Vitis vinifera, known as grapes, is a member of the Vitaceae family, native to the Mediterranean, Central 


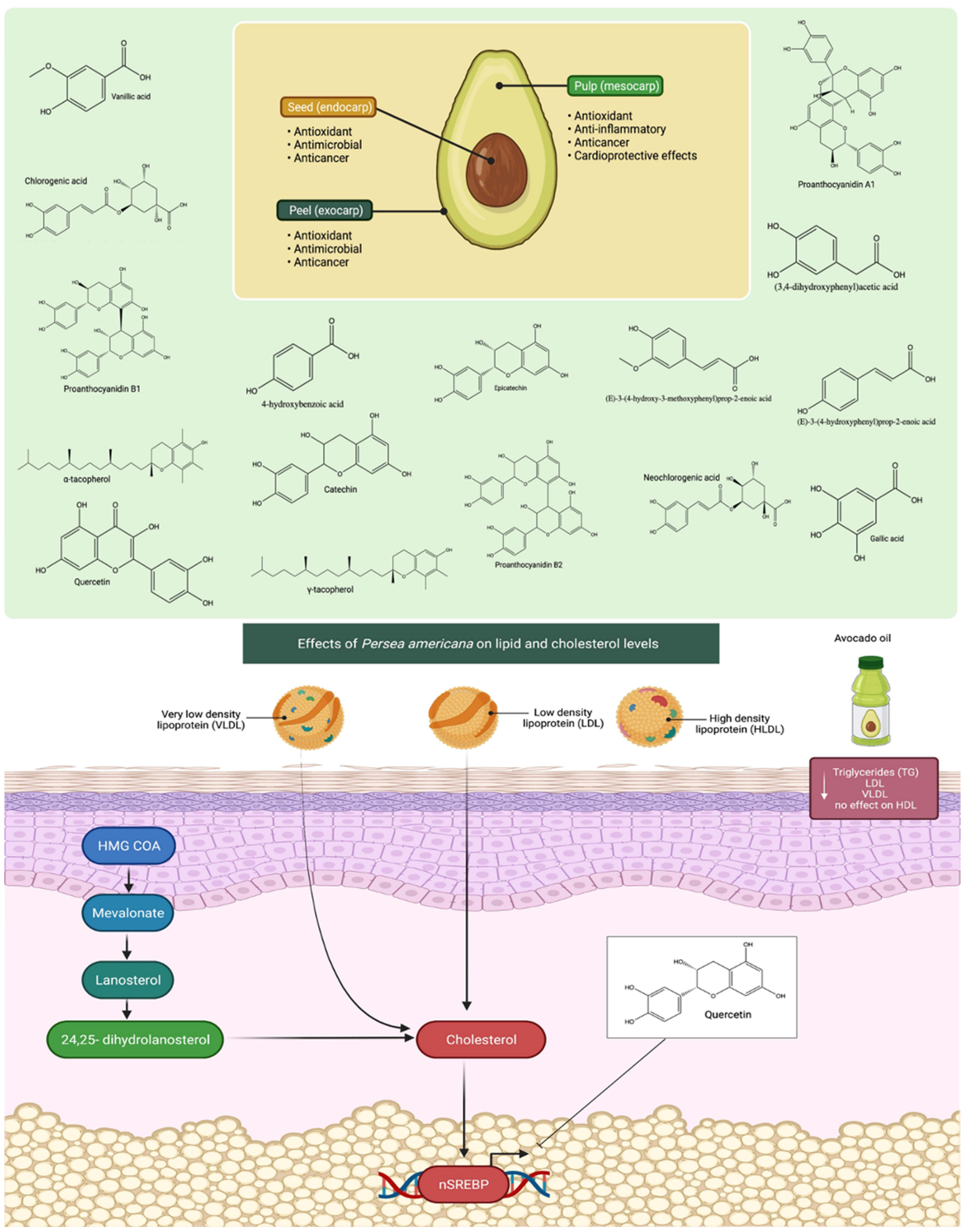

Figure 4 Bioactive compounds found in avocados (Persea americana) and their influence on lipid and cholesterol levels. Avocados have a wide range of anticancer, antioxidant, and cardioprotective properties, including reducing cholesterol levels, due to the compounds contained in the seed (endocarp), the pulp (mesocarp), and peel (exocarp). Increased lipid and cholesterol levels contributed to the development of heart disease by clogging the arteries with fatty streaks. Avocado fruit and oil consumption reduces blood TG, LDL, VLDL levels. The mechanism of action involves inhibition of cholesterol synthesis. Avocado bioactive components such as quercetin may have the ability to decrease cholesterol levels via modulating HMG-CoA and SREBP.

Abbreviations: TG, triglycerides; LDL, low-density lipoprotein; VLDL, very low-density lipoprotein; HMG-CoA, 3-hydroxy-3-methylglutaryl coenzyme A; SREBP, sterol regulatory element-binding protein-2. 
Europe and southwestern Asia. Among other fruits, the grape is one of the richest sources of polyphenols. ${ }^{41}$ The clinical and observational studies have demonstrated that flavonoids, particularly flavanols, are the most abundant in grapes and other berries. ${ }^{42}$ As such, they also possess more health benefits, especially in CVDs. ${ }^{43}$ For example, the intake of flavonoids clearly shows an inverse relationship with the risks of getting CVDs in which the higher the amount of flavanols taken, the lower the risk of getting CVDs.

Furthermore, grape extracts mitigated cardiac and cerebral ischemia damages caused by ischemia/reperfusion (I/ $\mathrm{R}$ ), which resulted in a significant increase in oxidative stress. ${ }^{44}$ Furthermore, a study looked into the connection between grape seed and skin extract in ischemic stroke. The findings revealed that the extracts reduced the size and histology of brain damage caused by $\mathrm{I} / \mathrm{R}$ and inhibited oxidative stress and enhanced transition metal-related enzyme activities. ${ }^{44}$ It has been demonstrated that polygalloyl-polyflavan-3-ols are highly abundant in grape skin and are a potent inhibitor of human platelet aggregation and LDL-oxidation. ${ }^{45}$

According to the study by MacMahon et al, ${ }^{46}$ high levels of TC could lead to ischemic heart disease and atherosclerosis, particularly among the eldest. Other parameters, such as an increase in LDL-c and low levels of HDL-c concentrations could also lead to CVDs. ${ }^{47} \mathrm{An}$ investigation has been done on grapes to prove their cardioprotection. ${ }^{48}$ The results showed that grapes prevented oxidative stress, conferred a positive effect on blood lipids, reduced LDL-oxidation (LDL-ox) and improved endothelial function effectively. Besides, the observation also indicated that grapes could minimise inflammation, inhibit platelet aggregation and decrease blood pressure. Apart from these, multiple clinical studies have been done on the cardioprotective benefits of grapes and berries. Thus, results suggested that any product derived from grapes and other berries is recommended for a cardiovascular prevention diet. Research on rats with metabolic syndrome looked into the anti-hypertensive effect and function of red grape berry powder. According to the findings, grape berry powder lowers blood pressure by inhibiting ET-1 secretion and rising endothelial nitric oxide synthase (eNOS) levels in a concentration-dependent manner (Figure 5). ${ }^{49}$ Furthermore, because of the direct impact of its polyphenol content on human umbilical vein endothelial cells, a study in vitro found that $1 \mathrm{~g} /$
$\mathrm{mL}$ grape seed extract decreased platelet reactivity by about $10 \%{ }^{50}$

Resende et $\mathrm{al}^{51}$ evaluated whether adult male rats, fed with a high-fat diet ( $24 \%$ fat), could protect by grape skin extract $(100 \mathrm{mg} / \mathrm{kg})$ from hypertension later in life. The results showed that adiposity, plasma TG levels, glucose levels, insulin resistance and oxidative stress were reversed by grape skin extract. ${ }^{51}$ Grapes' extract (375 $\mathrm{mg} / \mathrm{kg}$ ) had an antihypertensive effect in spontaneously hypertensive rats, which was very similar to captopril (50 $\mathrm{mg} / \mathrm{kg}$ ), a very common antihypertensive medication in clinical practice. ${ }^{52}$ Another research found that one of the active constituents in grapes (myricetin, 100 and 300 $\mathrm{mg} / \mathrm{kg}$, P.O. for 6 weeks) significantly decreased systolic blood pressure and vascular reactivity changes to catecholamines, as well as reversed the metabolic changes caused by fructose (serum glucose, cholesterol, TG, insulin and insulin resistance index). Besides, grape skin extract also possessed antihypertensive and antioxidant effects, which was confirmed in deoxycorticosterone acetate (DOCA)salt induced model in rats. ${ }^{53,54}$

The cardioprotective effect of grape extracts rich in malvidin, an anthocyanin extracted from red grape skin, was investigated on isolated and Langendorff perfused rat heart. Malvidin activated the $\mathrm{PI} 3 \mathrm{~K} / \mathrm{NO} /$ cyclic guanosine monophosphate (cGMP)/protein kinase-G (PKG) pathway, increasing intracellular cGMP and phosphorylation of eNOS, PI3K-AKT, extracellular regulated kinase $1 / 2$ (ERK1/2), and glycogen synthase kinase-3 $\beta$ (GSK-3 $\beta$ ) pathways, resulting in cardioprotective effects. ${ }^{55}$ It has been suggested by Dohadwala and Vita, ${ }^{56}$ the consumption of grape wine could also decrease the risk of CVDs, where it confers more health benefits than other alcoholic beverages. Similarly, Leifert and Abeywardena ${ }^{57}$ have also revealed that either grape or grape extracts, including grape juice, grape seeds and its skin, possess positive results in preventing some inflammatory-mediated diseases, including CVDs.

\section{Mango (Mangifera indica)}

Mangifera indica is an important plant of the world's indigenous medical systems. It is also known as Mango and distributed across the globe. Mango is one of the very wellknown tropical fruits with high amounts of nutrients. ${ }^{58} \mathrm{~A}$ broad range of mango cultivars show variations in colour, size, shape and composition in fruit peel worldwide. In addition to being eaten fresh, mango is also used to make juices, desserts, pickles and jam production. ${ }^{59}$ Numerous 

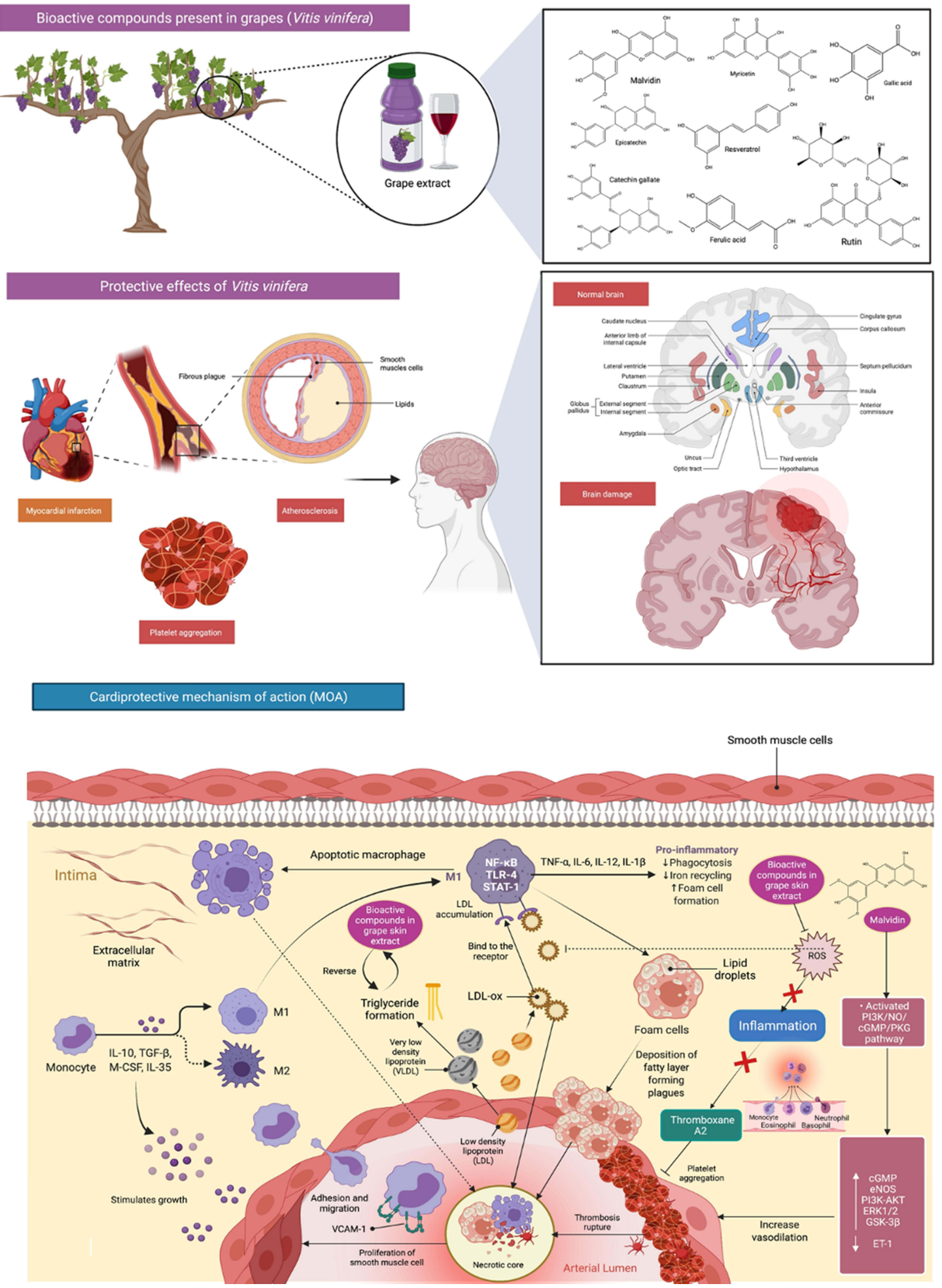

Figure 5 Bioactive compounds present in grapes (Vitis vinifera) and its mechanisms of action in cardioprotection. Grape extracts significantly reduced cardiac and brain ischemia-induced oxidative stress. Grapes contain compounds that assist avoid oxidative stress, thus resulted in a significant impact on blood lipids such as decreasing LDLoxidation (LDL-ox) and substantially enhance endothelial function. Additionally, it contributes to platelet aggregation inhibition, inflammation, and blood pressure reduction by decreasing endothelin-I (ET-I) secretion and increasing endothelial nitric oxide synthase (eNOS) levels.

Abbreviations: IL- I0, interleukin- I0; TGF- $\beta$, transforming growth factor beta; M-CSF, macrophage-colony stimulating factor; COX, cyclooxygenase; LOX, lipoxygenase; NFkB, nuclear factor kappa B, IL-35, Interleukin 35; VCAM-I, vascular cell adhesion protein I; IL-6, Interleukin 6; IL-I2, Interleukin I2; IL-I $\beta$, Interleukin I beta; PI3K/NO/cGMP/PKG, phosphoinositide 3-kinases/nitric oxide/cyclic guanosine monophosphate/protein kinase-G; PI3K-AKT, phosphoinositide 3-kinases/protein kinase B; ERKI/2, extracellular regulated kinase I/2; GSK-3 3 , glycogen synthase kinase-3 $\beta$. 

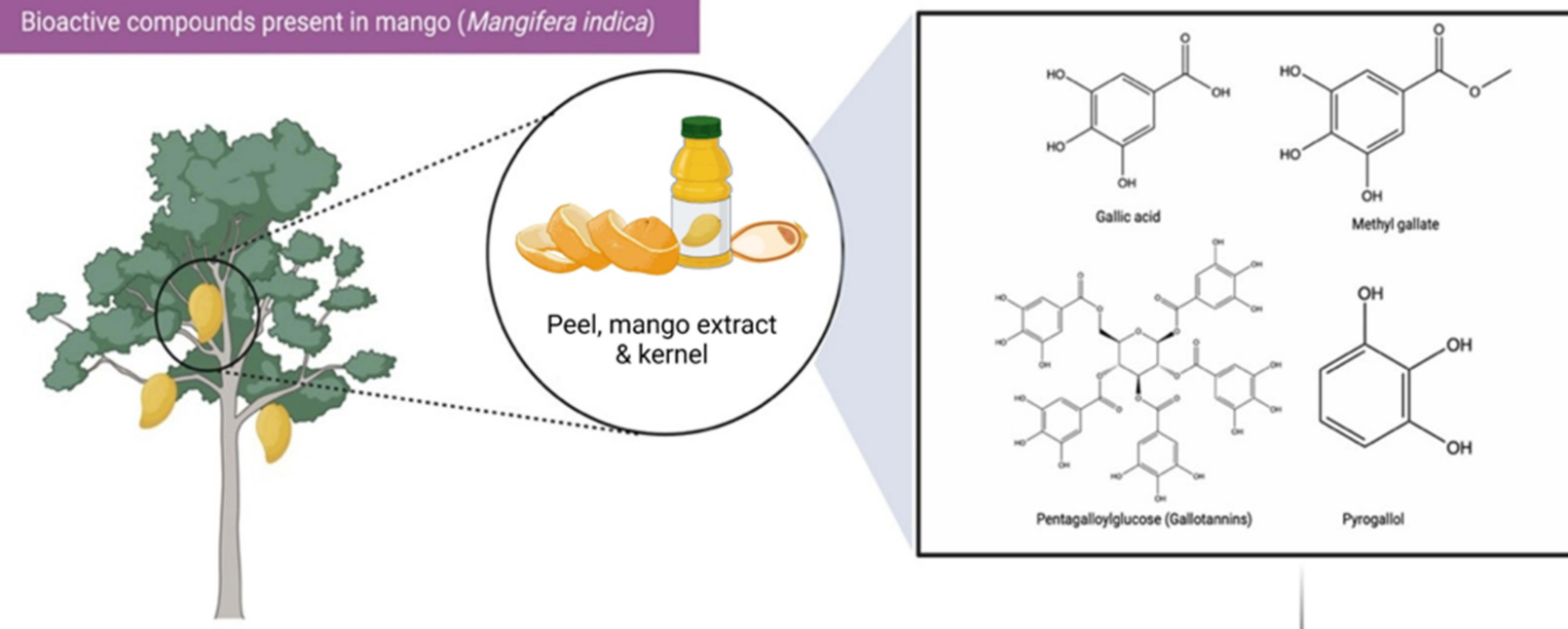

Cardioprotective effect of Mangifera indica

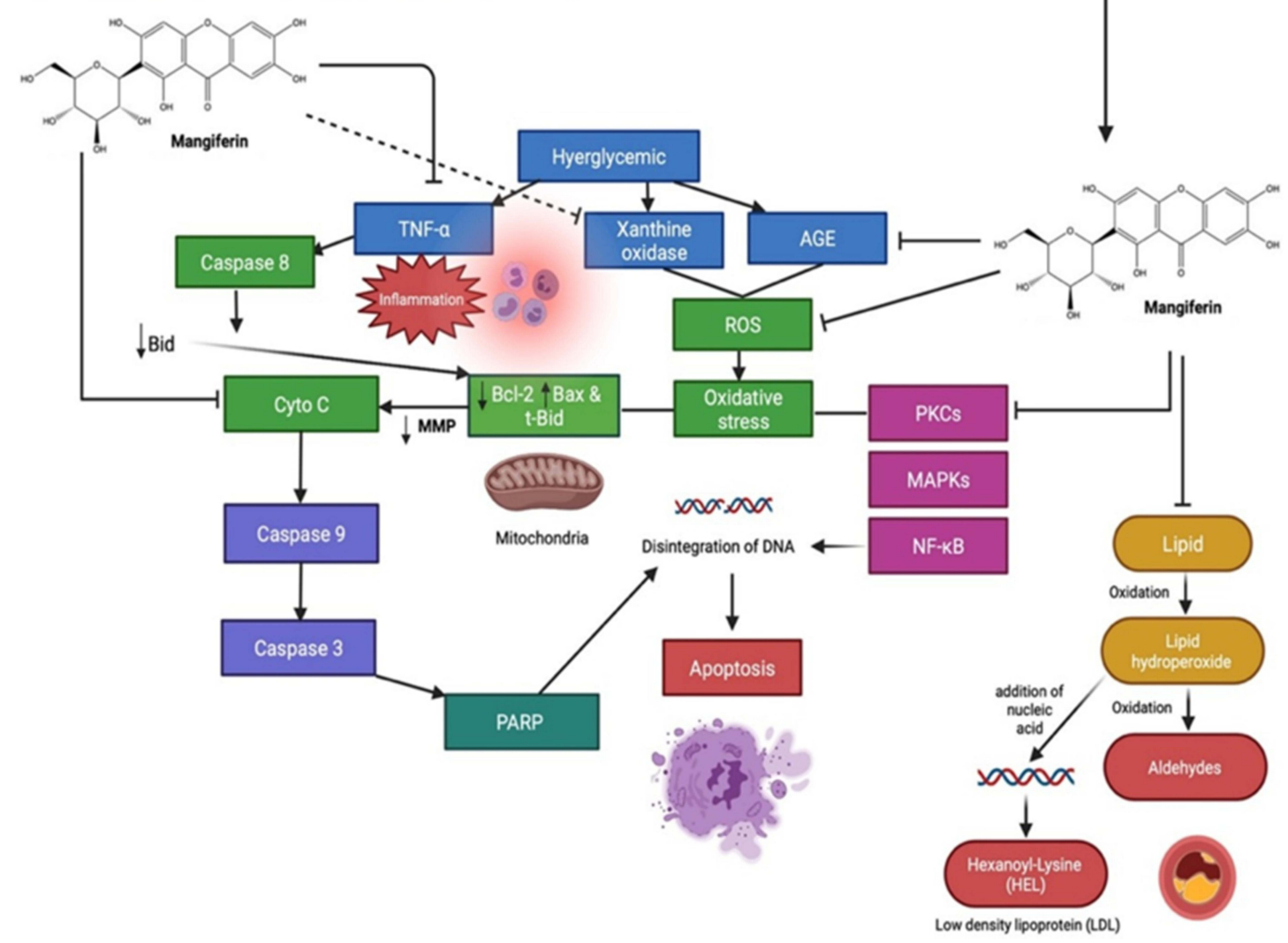

Figure 6 Bioactive compounds and cardioprotective effects of Mango (Mangifera indica). Mango has a high concentration of well-known bioactive components, such as vitamin C, carotenoids, and polyphenols. The strong oxidative impacts of reactive oxygen species (ROS) have been demonstrated to cause damage to biological molecules (eg, proteins, lipids, and nucleic acids) via structural and functional alterations. One of the phenolic compound present, Mangiferin which is highly abundant in Mango, have claimed to be important nutritional antioxidants in preventing and treating several chronic disorders, specifically CVDs by blocking the activation of pro-apoptotic signals, AGE, TNF- $\alpha$, ROS and lipid peroxidation.

Abbreviations: AGE, advanced glycation end products; TNF- $\alpha$, tumour necrosis factor $\alpha$; Bcl-2, B-cell lymphoma 2; Bax, Bcl-2-associated X protein; t-Bid truncated Bid; Cyto C, cytochrome complex; poly (ADP-ribose) polymerase (PARP); PKCs, protein kinase C isoforms; MAPKs, mitogen-activated protein kinases; NF-kB, nuclear factor kappa B. 
studies have identified the pharmacological properties of mango, including the cardioprotective effect.

Mango contains a huge amount of well-known bioactive compounds, including vitamin $\mathrm{C}$, carotenoids and polyphenolic compounds, ${ }^{60}$ which could reduce the risk factors of these CVDs, such as high-fat (HF) diet, dyslipidaemia and visceral adiposity. Besides, myocardial infarction is an acute condition caused by an imbalance between the coronary artery and the myocardium. Mangiferin, which is highly abundant in the peel, seeds and kernel parts of mango, shows a protective effect against myocardial infarction in rats. It was found that pretreatment with mangiferin $(10 \mathrm{mg} / 100 \mathrm{~g}$ body weight for 28 days) reduced the effect of isoproterenol-induced pathological changes, reduced lipid peroxide formation and kept myocardial marker enzyme activities near normal. The above findings suggest that mangiferin has a cardioprotective function in rats. ${ }^{61}$ Strong oxidation effects of reactive oxygen species (ROS) have shown to cause damage to biological molecules (eg, proteins, lipids and nucleic acids) associated with their structural and functional changes (Figure 6). Vitamin $\mathrm{E}$, vitamin $\mathrm{C}$ and $\beta$-carotene, which are highly abundant in mango, have claimed to be important nutritional antioxidants in preventing and treating several chronic disorders, specifically CVDs. ${ }^{62}$

\section{Orange (Citrus sinensis)}

Citrus sinensis is known as orange belongs to Rutaceae family. It has been widely used traditionally for the prevention and treatment of CVDs. The intake of orange juice has been shown in multiple studies to alleviate the incidence of CVDs risk factors, such as hyperglycaemia, oxidative or inflammatory stress, dyslipidaemia, hypertension, endothelial dysfunction and obesity. ${ }^{63}$ Recently, a study has been done to investigate the effects of orange juice on the activities of monoamine oxidase (MAO), phosphodiesterase (PDE) and angiotensin-converting enzyme (ACE) in the rat heart. ${ }^{64}$ From the observations, orange juice significantly inhibited PDE, MAO and ACE activities in the rat heart homogenate (Figure 7). Orange juice also reduced the production of $\mathrm{Fe}^{2+}$-induced malondialdehyde in a concentration-dependent manner. The findings indicated that orange could be used as a treatment regimen to prevent and control CVDs by inhibiting the enzymes and preventing oxidative damage. ${ }^{64}$

Interestingly, Asgary and Keshvari ${ }^{65}$ reported that the healthy volunteers fed with $500 \mathrm{~mL}$ of commercial orange juice twice a day for 4 weeks reduced their diastolic and systolic blood pressure. In contrast, natural orange juice, on the other hand, had no significant effects on diastolic or systolic blood pressure after 4 weeks of administration. ${ }^{65}$ Castello et $\mathrm{al}^{66}$ have also been conducted fermentation phase using orange juices. Bioactive compounds and moderate alcohol consumption reduce the risk of CVDs. These effects could be combined in a beverage made from orange juice that has undergone a regulated alcoholic fermentation. Escudero-López et $\mathrm{al}^{67}$ investigated the impact of regulated alcoholic fermentation on the bioactive compound profile of orange juice. In fact, fermentation processes have been proved in helping to retain bioactive components that have been degraded as a result of specific thermal treatments used in the juice industry, or to alter the phytochemical profile for a given food matrix. Thus, the obtained results are due to the higher concentration of bioactive compounds.

In addition, the impact of controlled alcoholic fermentation on the composition of orange juice can significantly increase the content of flavanones, carotenoids and melatonin, as well as antioxidant capacity. It has been reported that most of the bioactive effects of orange juice, particularly those with fermentation, are due to the presence of flavanones, which are broadly associated with the reduced risk of chronic disease, specifically cardiovascular problem. ${ }^{68}$ Flavanones are a subgroup of flavonoids and mainly found in the peel and fleshy segment. ${ }^{69}$ Castello et $\mathrm{al}^{66}$ compared the bioavailability of orange flavanones and other phenolic compounds contained in a fermented orange juice beverage to the bioavailability of the corresponding orange juice substrate in humans. They observed that polyphenols were rapidly absorbed with the fermented orange juice as compared to after consumption of orange juice.

It is noted that cardiovascular drugs are prescribed for and/or used to treat a wide range of illnesses, conditions and diseases that affect the cardiovascular system, but they may also have harmful levels, side effects and/or adverse effects in certain cases. Collectively, the above studies indicated that oranges could be used to therapeutically treat CVDs and are potentially healthy. Thus, it is suggested to consume orange juice or fermented products as the cardioprotective mechanisms still remain by preventing oxidative stress and maintaining lipid profile.

\section{Kiwifruit (Actinidia deliciosa)}

Kiwifruit or Actinidia deliciosa belongs to the Actinidiaceae family and it is a native plant in Eastern Asia. It possess a high quantity of vitamin $\mathrm{C}$, vitamin $\mathrm{E}$, folic acid and other phytochemicals, such as flavonols and 


\section{Bioactive compounds present in orange (Citrus sinensis)}
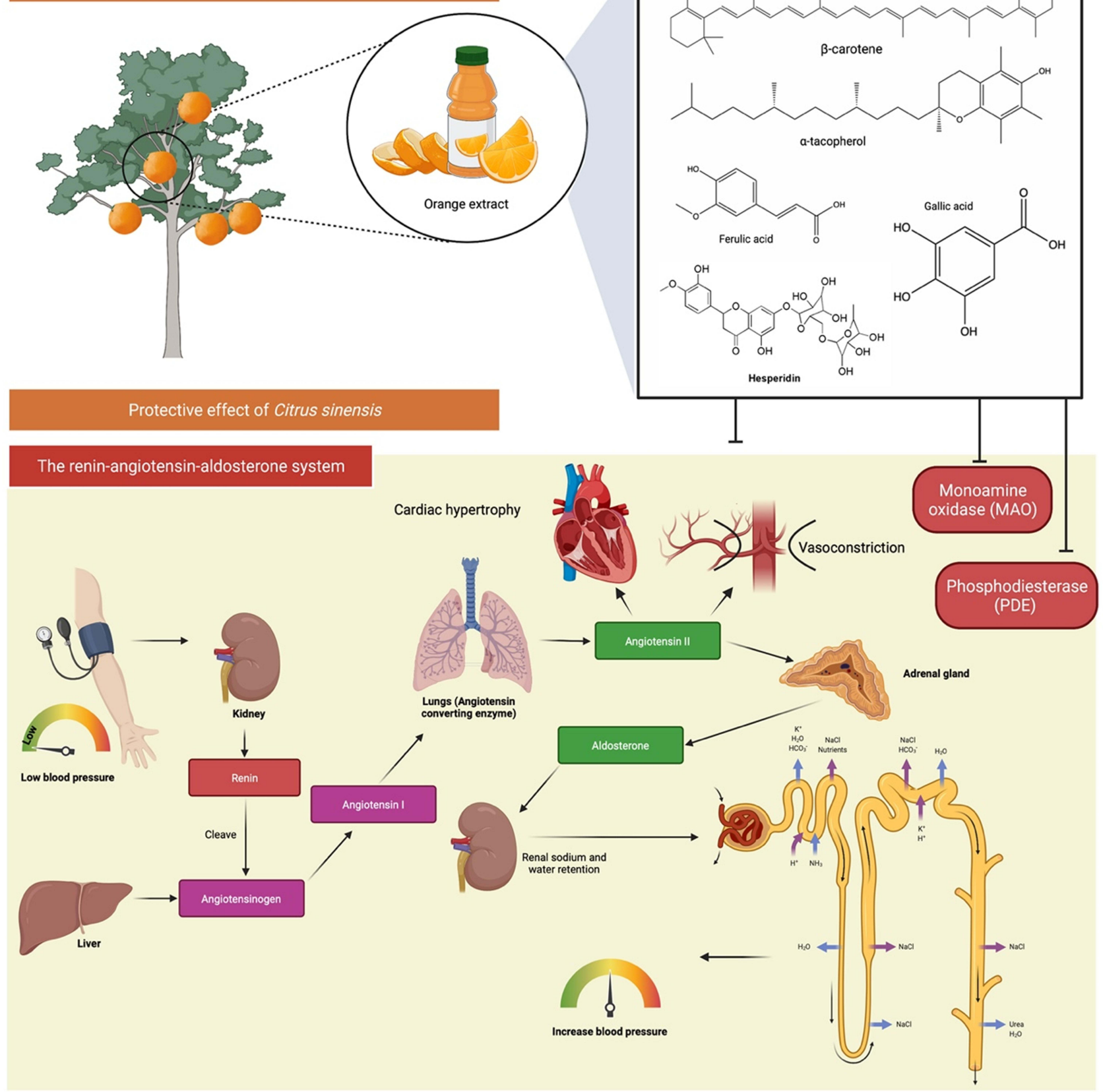

Figure 7 Bioactive compounds and protective effects of orange (Citrus sinensis) in on the monoamine oxidase (MAO) activity, phosphodiesterase (PDE) activity, and angiotensin-converting enzyme (ACE) activity in the heart. Orange extract/juice contains compounds that helps in modulation of the renin-angiotensin-aldosterone system (RAAS) thus helps in lowering the diastolic and systolic blood pressure.

anthocyanidins. ${ }^{70}$ Besides, Ru et al ${ }^{71}$ also determined that kiwifruit was high in antioxidant compounds, such as vitamin $\mathrm{C}$, flavonoids, carotenoids and phenolic components. The soluble fiber in Kiwifruit can also improve dietary lipid absorptions and reabsorptions. In comparison to gold kiwifruit, green kiwifruit is more commonly used to study the therapeutic effects on CVDs. ${ }^{72}$
The study by Duttaroy and Jørgensen ${ }^{73}$ found that eating kiwifruit could reduce platelet reactivity to collagen and adenosine diphosphate (ADP) in human volunteers. The results also showed that kiwifruit was able to improve the efficacy of thrombosis prophylaxis. Intriguingly, regular consumption of green and gold kiwifruit may also positively impact on certain 
physiological biomarkers, particularly in people with metabolic disorders linked to CVDs. ${ }^{74}$ For instance, in a randomised controlled trial of 85 normotensive and pre-hypertensive hypercholesterolemia men, Gammon et $\mathrm{al}^{75}$ discovered that eating two green kiwifruits per day for 4 weeks significantly improved plasma lipid profile as compared to eating a balanced diet alone. Atherosclerosis is often considered as a heart disease, where it refers to build-up of fats, oxidised cholesterol and other substances in and on the artery walls. The accumulation of these substances form plaque gradually, leading to blood flow restriction. The plaque can then be burst to trigger a blood clot that causes CVDs. Jung et $\mathrm{al}^{76}$ reported that kiwifruit can help to prevent CVDs, as it acts as antioxidants and shows fibrinolysis activity with inhibitory action against ACE and HMG-CoA reductase. ${ }^{76}$

Svendsen et $\mathrm{al}^{77}$ found that adding three kiwifruits to the regular diet was correlated with lower systolic and diastolic 24-hour blood pressure in men and women aged 35 to 69 years with moderately elevated blood pressure as compared to one apple per day. ACE is essential in controlling blood pressure via renin-angiotensin system. As hypertension is a well-known risk factor for atherosclerosis, there is a growing interest in identifying food sources that act as ACE inhibitors. Besides, as reported in the observational study, it was interesting to note that eating fruits every day, particularly kiwifruit, could enhance the fibrinolytic system, which may result in a lower risk of thromboembolic and CVDs. Besides, Padmanabhan and Paliyath $^{78}$ discovered the health-promoting benefits of kiwifruit by comparing a healthy control diet with the consumption of two green kiwifruits every day for 4 weeks. It was observed that kiwifruit could regulate apolipoprotein B/apolipoprotein A1 ratio and plasma HDL-c TC/HDL-c ratio in hypercholesteraemic men. Meanwhile, another researcher group also found that male smokers had a drastic lower diastolic and systolic blood pressure than the control group after eating three green kiwifruits per day for 8 weeks. ${ }^{79}$ This study further discovered that kiwifruit reduced TG levels in the blood, indicating its potential in preventing atherosclerosis.

Consumption of high-fibre fruits has long been linked to the reduced risk of chronic diseases in humans, including CVDs. ${ }^{80}$ Green and gold kiwifruit are extremely rich in vitamins $\mathrm{C}, \mathrm{E}, \mathrm{K}$, folate, carotenoids, potassium, fibre and phytochemicals, which work together to provide many health benefits. As part of a healthy diet, kiwifruit can help in raise HDL-c while lowering TG, platelet aggregation and blood pressure. $^{74}$ Vitamin $\mathrm{C}$, vitamin $\mathrm{E}$, polyphenols, ${ }^{81}$ a favourable $\mathrm{Na}^{+} / \mathrm{K}^{+}$ratio ${ }^{82}$ and other bioactive components in kiwifruit can justify their physiological benefits. $^{74}$

\section{Pomegranate (Punica granatum)}

Punica granatum, also known as pomegranate, is a common plant that belongs to the Punicacceae family. Pomegranates are widely cultivated throughout the world. In a study conducted by Mohan et $\mathrm{al}^{83}$ using streptozotocin-induced diabetic Wistar rats with angiotensin IIinduced hypertension, it was interested to note that a prolonged administration of pomegranate juice $(100 \mathrm{mg} /$ $\mathrm{kg}$ and $300 \mathrm{mg} / \mathrm{kg}$, P.O. for 4 weeks) significantly decreased ACE activity mean arrhythmia, indicating that it has antihypertensive action. These results can further contribute to an antioxidant environment and reduce the risk of atherosclerosis. ${ }^{83}$ Additionally, the effect of pomegranate extract on coronary artery atherosclerosis in SRBI/apoE double knockout mice was also evaluated. The treatment of pomegranate extract reduced aortic sinus and coronary artery atherosclerosis. Despite unmodified systemic markers of inflammation and increased lipoprotein cholesterol in the treated mice; however, pomegranate extract treatment was able to exert atheroprotective effects by reducing oxidative stress and inflammatory effects on the blood vessel wall. ${ }^{84}$

Pomegranate was reported to have abundant antioxidants and strong anti-hypertonic properties, either in peel, seed, or juice. ${ }^{85}$ Interestingly, punicalagina, the main bioactive component of pomegranate, has been shown to have cardiovascular protection via its potent antioxidant activity. ${ }^{86}$ Pomegranate seed extract also enhanced motor and cognitive deficits caused by chronic cerebral hypoperfusion ischemia, which was most likely due to its antioxidant and free radical scavenging properties. ${ }^{87}$ In fact, high levels of oxidative stress in the hypothalamic paraventricular nucleus play a role in the pathogenesis of hypertension. $^{88}$ In line with these, Sun et al, (2016), found that pomegranate extracts could relieve the health condition of spontaneously hypertensive rats by lowering oxidative stress, decreasing inflammation, increasing antioxidant defences and improving mitochondrial function in the paraventricular nucleus and also AMPK-nuclear factor-erythroid $2 \mathrm{p} 45$-related factor $2(\mathrm{Nrf} 2)$ pathway is thus activated in the paraventricular nucleus. ${ }^{89}$ 
The protective effects of pomegranate fruit extracts against cardiac toxicity caused by drugs or smoking were also investigated. For instance, pretreatment of pomegranate juice for 30 days in isoproterenol-induced cardiac necrosis rats diminished the cardiotoxicity of isoproterenol..$^{90}$ Additionally, pomegranate juice significantly suppressed the increased heart weight, infarction size, plasma marker enzymes, lipid peroxidation levels and $\mathrm{Ca}^{2+}$ adenosine triphosphatase (ATPase) levels. ${ }^{90}$ The prevalence of CVDs is associated with a higher incidence of obesity as well. ${ }^{85}$ Previous research has shown that excessive fat build-up might boost ROS generation and develop oxidative stress, as well as morphological changes that ultimately cause heart damage. ${ }^{91}$ In addition, the accumulation of fats in obese people might cause several other risk factors, including mitochondrial dysfunction. ${ }^{92}$ Thus, it is crucial for obese people to improve their obesity-associated cardiac dysfunction. The cardioprotective effect of pomegranate extract against obesity-induced cardiac dysfunction has been evaluated. In a rodent obesity model, Shao et $\mathrm{al}^{93}$ demonstrated that pomegranate extract activated AMP-activated protein kinase (AMPK) by reducing the cellular ATP/ADP ratio in cardiomyocytes. ${ }^{93}$ The activation of AMPK pathway has contributed to the prevention of mitochondrial loss by improving mitochondrial biogenesis and ameliorating oxidative stress through increased Phase II enzyme activity in high-fibre diet-induced CVDs. ${ }^{93}$

In an animal model, cigarette smoking is linked to major cardiovascular pathology including cardiac hypertrophy, inflammation, pro-fibrotic and atherogenic markers and aortic calcification. A study reported that pomegranate juice administration exhibited protection against cigarette smoke-induced cardiac hypertrophy in a rat model. ${ }^{84}$ Furthermore, a pomegranate peel hydroalcoholic extract was shown to decrease cardiovascular risk factors in obese women with dyslipidaemia in a double-blind, randomised and placebo-controlled pilot trial. ${ }^{94}$ Overall, the reviewed studies showed that using pomegranate fruit and its constituents as dietary supplements or adjuvants in the treatment of vascular diseases, including hypertension, coronary artery disease and peripheral artery disease, may have significant benefits.

\section{Papaya (Carica papaya)}

Papaya or Carica papaya belongs to the family of Caricaceae. It is one of the largest fruit productions located in tropical and subtropical regions. It has been reported to possess various pharmacological properties contributed by different parts. For example, the pulp contains vitamins A, B complex, E complex and vitamin $\mathrm{C}$, such as pantothenic acid, folic acid, and minerals like magnesium and potassium. These compounds are significant antioxidants that are present in papaya. ${ }^{95}$ The nutrients found in papaya have shown beneficial effects, including a substantial improvement in the cardiovascular system, protecting against CVDs, heart attacks and strokes. ${ }^{96}$ Beneficial effects have been noted, with a noticeable improvement in the cardiovascular system, protecting against cardiovascular diseases, heart attacks and strokes, due to the nutrients found in papaya composition. ${ }^{96}$ Papaya fruit-seed has been shown to contain phenolic compounds, such as carotenoids and $\beta$-carotene, while the leaves have a high amount of food fibre, flavonoids and polyphenolic compounds. As papaya has a high fibre content, it has been reported to reduce fat absorption and prevent free radicalsinduced damages. The vascular effects of papaya seed extracts at high concentrations are consistent with the notion that benzyl isothiocyanate is the main bio-active ingredient. $^{96}$

Gayosso-García et $\mathrm{al}^{97}$ and Hiraga et $\mathrm{al}^{98}$ assessed the antioxidant content of papaya fruits with different maturity. The whole papaya fruit was chosen based on their visual maturity and classified into four stages of maturity from green to light yellowish. Interestingly, the result demonstrated that the green papaya fruit, which is at the lowest maturity stage, exhibited extremely high antioxidant activity, as it had relatively higher phenol content as compared to other maturity stages. Given antioxidant has cardioprotective effects, it is recommended for CVD patients to take the unripe green papaya fruits. It has been known that prediabetic people are at risk for CVDs. Subsequently, papaya is also said to have antihypertensive effects, as hypertension is closely related to CVD as well. In a normotensive, renal and DOCA-salt hypertensive animal model, the ethanolic extract of papaya unripe fruit $(20 \mathrm{mg} / \mathrm{kg}$, i.v. $)$ significantly reduced arterial blood pressure, indicating its unripe fruits have potent anti-hypertensive properties. ${ }^{99}$

Moreover, the antihypertensive effects of a standardised papaya methanolic extract were investigated in spontaneously hypertensive rats. Brasil et $\mathrm{al}^{100}$ showed that the ACE-inhibitory effect of papaya on the plasma reduced the cardiac hypertrophy to the levels as similar to the treatment group receiving enalapril, which is used as ACE inhibitor drug to treat high blood pressure. These findings may be contributed by the chemical properties of papaya 
methanolic extract containing flavonoids, such as quercetin, nicotiflorin, clitorin and manghaslin, which has been reported as bioactive components in papaya extracts to treat hypertension. ${ }^{100}$ Thus, this research represents in developing a new phytotherapy agent from papaya specifically for hypertension treatment.

\section{Pineapple (Ananas comosus)}

Ananas comosus is a tropical plant that bears pineapple fruit and is well known worldwide. It is a member of the Bromeliaceae family. They are widely consumed around the world and are easy to incorporate into everyday diets. It is high in dietary fibre as well as phytochemicals like bromelain, gallic acid, catechin, epicatechin and ferulic acid. ${ }^{101}$ Pineapple has been studied biologically and is found to be highly effective against CVDs due to several therapeutic properties. Pineapple contains many biological constituents, such as bromelain, that are responsible for health benefits. ${ }^{102}$ Bromelain was discovered in the late nineteenth century as the main component in pineapple, which is a protein extract that can be found in the pineapple fruit. ${ }^{103}$ Seenak et al ${ }^{101}$ reported that the pineapple has antioxidant and lipid-lowering effects, so regular intake will minimize hypercholesterolemia-induced cardiac lipid peroxidation and pro-inflammation in an in vivo model. Pineapple has been shown to be a possible candidate for cardioprotection against hypercholesterolemia in this study. According to Saxena and Panjwani, ${ }^{104}$ hydro-alcoholic fruit extract of pineapple has high antioxidant activity and can protect cell membrane integrity while also improving cardiac systolic/diastolic dysfunction caused by isoproterenol. It was also found that pineapple was more efficient in reducing the degree of myocardial damage and substantially counteracting oxidative stress in the rat model of isoproterenol-induced myocardial infarction. $^{104}$

Angina pectoris and ischemic attacks are life-threatening symptoms caused by thrombus formation in the heart's blood supply. A blood clot blocks the blood flow of one or more veins in thrombophlebitis. Bromelain's effect in these situations has been studied and found to be successful at breaking up clots by interacting with fibrinogen, allowing blood to circulate freely through the blood vessels. ${ }^{105}$ Cardiac dysfunction can always relate to the massive formation of a thrombus that causes damage to the blood supply, resulting in lethal complications, such as Ischemic Heart Disease (IHD) and Angina pectoris. Likewise, blood clot blocks blood supply in one or more veins in thrombophlebitis. Interestingly, the therapeutic potentials of bromelain has been studied in cardiac dysfunctions. When bromelain (400 $\mathrm{mg}$ to $1 \mathrm{~g}$ ) given orally to 14 patients with angina pectoris, it was found to eliminate all symptoms that contribute to diabetic and cardiovascular complications. Bromelain was reported to be involved in the reperfusion of skeletal muscles following ischemic disease. ${ }^{106,107}$ Similarly, Juhasz et al $^{108}$ also found that Bromelain exerted cardio protection against ischemiareperfusion injury in rat myocardium. For instance, Go et $\mathrm{al}^{109}$ reported that approximately $65 \%$ of the diabetic patients die from stroke or heart disease, as they are the main cause of death. Moreover, on the basis of National Health and Nutrition Examination Survey (NHANES), 2003-2006 data showed that a group of obesity, overweight and insulin resistance are predominantly associated with cardiovascular risk factors. ${ }^{109}$

Thus, Bromelain was found to be very effective in inhibiting the blood platelet aggregation, which minimises the risk of getting arterial thrombosis and embolism and plays a big role in treating of CVDs. Daily pineapple consumption reduced the atherogenic coefficient and cardiac risk ratio in the same way that simvastatin treatment. As a result, pineapple is an excellent addition to a daily diet because it has an additional lipid-lowering effect that may enable the medication to be reduced while also serving as potential functional food for cardiovascular health. ${ }^{101}$

\section{Watermelon (Citrullus lanatus)}

Watermelon is a member of the Cucurbitaceae family and distributed all over the world. It is called a "pepo" by botanists, which is a fruit with a thick rind and fleshy center. It is widely consumed as a refreshing summer fruit and its refreshing ability, attractive color, delicate taste and high water content to quench summer thirst are highly valued by consumers. ${ }^{110}$ It has been reported that watermelon has a high amount of fibre, vitamins, minerals and bioactive constituents, including L-citrulline, lycopene and alpha, which are crucial in preventing CVDs. ${ }^{111}$ Multiple studies have evaluated the effects of watermelon, either in the form of juice or extract, on diminishing CVD risk factors. For instance, Connolly et $\mathrm{al}^{111}$ found that fresh watermelon fruit had good cardioprotective effects by reducing CVD risk factors in overweight and obese adults. Fresh watermelon fruit consumption significantly decreased body weight, body mass index (BMI), systolic blood pressure and waist-to-hip ratio. It also could normalise the lipid profile by reducing increased levels of 
triglyceride, LDL cholesterol and thiobarbituric acid reactive substances (TBARS) while increasing HDL-c and total antioxidant capacity. These observations indicated that fresh watermelon fruit taken daily could improve lipid profiles and biochemical parameters, lower blood pressure and enhance antioxidant capacity, all of which are important to treat and prevent CVDs.

Another study by Shanely et al $^{112}$ also supported that daily intake of watermelon reduced the risk of getting CVD in overweight and obese individuals. In this study, $100 \%$ pure and fresh watermelon was given 6 weeks to obese and overweight postmenopausal women whose are high-risk CVD people. Postmenopausal women have been reported to have relatively high amount of fats and prone to develop atherosclerosis. The results showed that watermelon could reduce the fat deposition and plaque formation, which are causes of promoting atherosclerosis and cardiac problem. ${ }^{112}$ Besides, watermelon consumption has also been related to be cholesterol-free and fat-free and increased levels of minerals and phytochemicals with low amount of sodium. ${ }^{113}$ It has antioxidant properties and possess good amount of vitamins, carbohydrates and fibre all of which possess are beneficial to protect cardiovascular system. Besides, watermelon has recently received recognition due to its low fat content as compared to other fruits and vegetables. ${ }^{110}$
Other than these, watermelon juice has also been reported to improve vascular health in hypertensive patients. According to the World Health Organization (WHO) reports, the vitamin content in watermelon juice is responsible for cholesterol management. The WHO has suggested that since everyone should consume low-fat and fibre-rich meals as part of their optimal diet, watermelon will be the best option. Watermelon juice and pulp have been shown to have a high fibre content, which can regulate blood cholesterol levels and prevent its associated cardiac problems. ${ }^{114}$

\section{Overview of the Mechanism of Nutritional Fruits Against CVDs}

Several studies have shown that nutritious fruits such as apple, avocado, grape, mango, orange, kiwifruit, pomegranate, papaya, pineapple, watermelon and their phytoconstituents have significant cardioprotective effects, as summarized in this review. Overall, the possible underlying mechanisms of action of nutritional fruits in protecting heart from CVDs are associated with 1) vascular protection, 2) blood pressure modulation, 3 ) reduction of cholesterol levels, 4) platelet-inhibiting function, 5) lipid-metabolism regulation, 6) oxidative stress reduction, and 7) ischemic or reperfusion reduction (Figure 8 and Table 2).

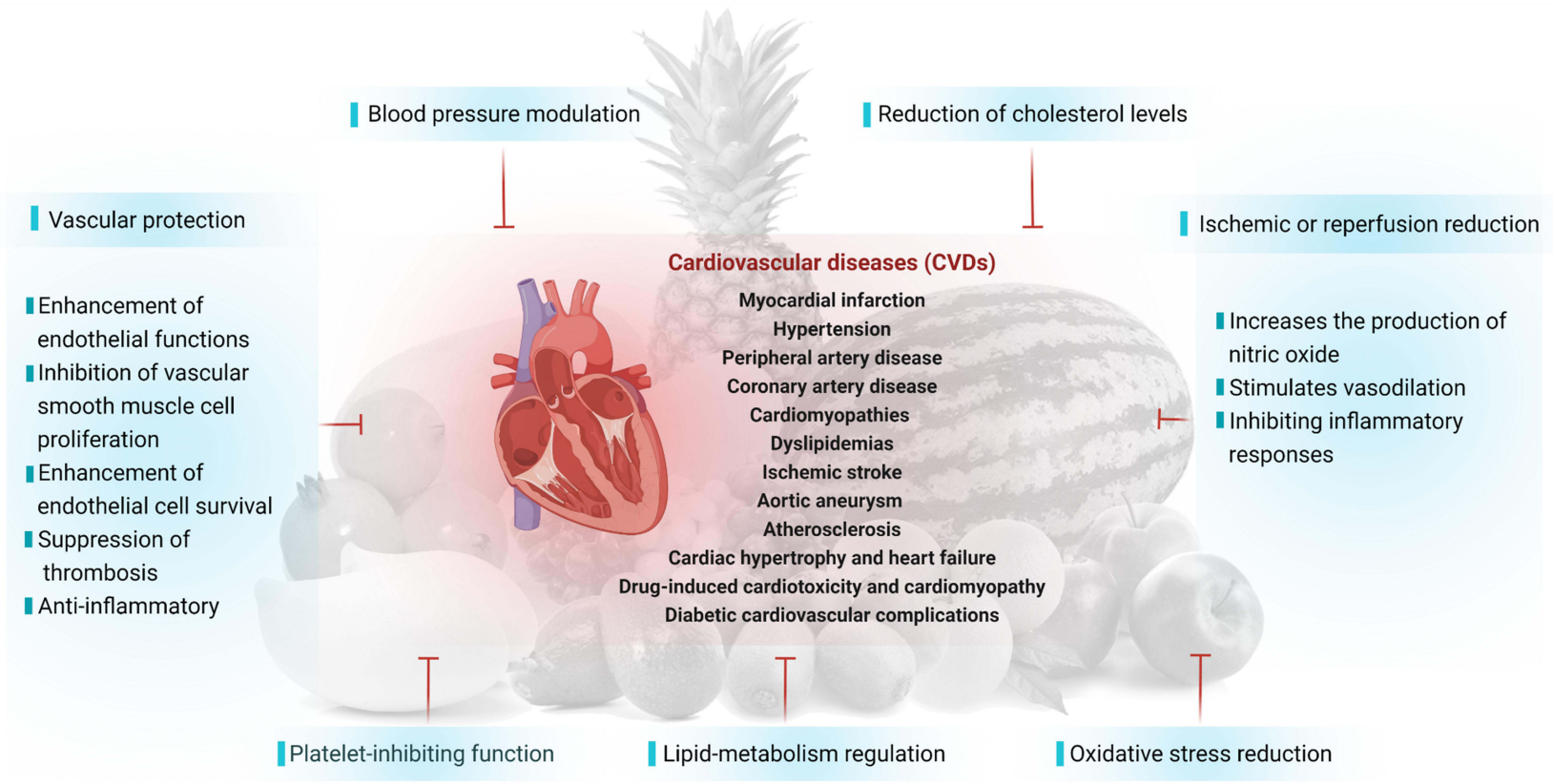

Figure 8 Possible mechanisms of action of nutritional fruits in protecting heart from CVDs. 
Table 2 Mechanism of Action of Nutritional Fruits Against CVDs

\begin{tabular}{|c|c|c|}
\hline $\begin{array}{l}\text { Nutritional } \\
\text { Fruits }\end{array}$ & Mechanism of Action & Reference \\
\hline Apple & $\begin{array}{l}\text { Protection of Vascular Endothelial Function } \\
\text {-By improving endothelial function } \\
\text { Blood Pressure Modulation } \\
\text {-By maintaining pulse rate and systolic blood pressure } \\
\text { Inflammation Reduction } \\
\text { - By lowering CRP level in the body } \\
\text {-By decreasing stroke mortality } \\
\text { - By decreasing serious stomach aortic calcification } \\
\text { Reduction of Cholesterol Levels } \\
\text {-By decreasing TC and LDL levels } \\
\text {-By increasing HDL levels }\end{array}$ & $\begin{array}{l}\text { Bondonno et al, }{ }^{23} \text { Hodgson et al, }{ }^{22} \text { Ravn-Haren et al, }{ }^{25} \text { Sandoval-Ramírez et al, }{ }^{21} \text { Serra } \\
\text { et al, }{ }^{29} \text { Gonzalez et al }{ }^{30}\end{array}$ \\
\hline Avocado & $\begin{array}{l}\text { Platelet-Inhibiting Functions } \\
\text { •By acting as anti-platelet and anti-thrombotic agents } \\
\text { Thrombosis Suppression } \\
\text { •By increasing coagulation times } \\
\text { •By reducing thrombus formation } \\
\text { Blood Pressure Modulation } \\
\text {-By inducing bradycardia, vasorelaxation and hypotension } \\
\text { Inflammation Reduction } \\
\text { •By decreasing the levels of high-sensitivity CRP } \\
\text {-By preventing the development of metabolic syndrome } \\
\text { Reduce Cholesterol Level } \\
\text { •By increasing serum HDL-c concentrations } \\
\text { •By decreasing TG, VLDL and LDL levels }\end{array}$ & $\begin{array}{l}\text { Carvajal-Zarrabal et al, }{ }^{33} \text { Gouegni and Abubakar, }{ }^{39} \text { Mahmassani et al, }{ }^{32} \text { Park et al, }{ }^{36} \\
\text { Rodriguez-Sanchez et al, }{ }^{38} \text { Dabas et al }{ }^{40}\end{array}$ \\
\hline Grapes & $\begin{array}{l}\text { Lipid-Metabolism Regulation } \\
\text { •By exerting a positive effect on blood lipids } \\
\text {-By inhibiting LDL oxidation } \\
\text { Protection of Vascular Endothelial Function } \\
\text { •By improving endothelial function } \\
\text { Platelet-Inhibiting Functions } \\
\text {-By inhibiting human platelet aggregation } \\
\text { Blood Pressure Modulation } \\
\text {-By preventing the production of high blood pressure } \\
\text {-By protecting from hypertension } \\
\text { Oxidative Stress Reduction } \\
\text {-By increasing antioxidant levels } \\
\text { Inflammation Reduction } \\
\text {-By preventing some inflammatory-mediated diseases }\end{array}$ & $\begin{array}{l}\text { Borde et al, }{ }^{53} \text { Godse et al, }{ }^{54} \text { Leifert and Abeywardena, }{ }^{57} \text { Resende et al, }{ }^{51} \\
\text { Shanmuganayagam et al, }{ }^{45} \text { Quiñones et al, }{ }^{52} \text { Leibowitz et al, },{ }^{49} \text { Luzak et al, }{ }^{50} \text { Quintieri } \\
\text { et al, }{ }^{55} \text { Safwen et al }{ }^{44}\end{array}$ \\
\hline Mango & $\begin{array}{l}\text { Lipid-Metabolism Regulation } \\
\text {-By reducing lipid levels in the induced dyslipidaemia model } \\
\text { - By reducing the risk factors of hyperglycaemia, HF diet, } \\
\text { dyslipidaemia and visceral adiposity } \\
\text {-By increasing serum HDL-c in the hyperlipidaemic model } \\
\text { Oxidative Stress Reduction } \\
\text {-By enhancing antioxidant activity } \\
\text { Reduce Cholesterol Level } \\
\text {-By preventing the rapid onset of the atherosclerotic } \\
\text { process }\end{array}$ & Fidrianny et al,$^{60}$ Prabhu et al $;{ }^{61}$ Lobo et a ${ }^{62}$ \\
\hline
\end{tabular}

(Continued) 
Table 2 (Continued).

\begin{tabular}{|c|c|c|}
\hline $\begin{array}{l}\text { Nutritional } \\
\text { Fruits }\end{array}$ & Mechanism of Action & Reference \\
\hline Orange & $\begin{array}{l}\text { Lipid-Metabolism Regulation } \\
\text { - By inhibiting the production of } \mathrm{Fe}^{2+} \text {-induced } \\
\text { malondialdehyde in a concentration-dependent manner } \\
\text { - By enhancing the lipid profile and peroxidation } \\
\text { Blood Pressure Modulation } \\
\text { - By reducing diastolic and systolic blood pressures } \\
\text { Oxidative Stress Reduction } \\
\text { - By enhancing antioxidant activity } \\
\text { - By preventing oxidative damage } \\
\text { Inflammation Reduction } \\
\text { - By inhibiting MAO, PDE and ACE activities }\end{array}$ & Ademosun and Oboh, ${ }^{64}$ Asgary and Keshvari, ${ }^{65}$ Castello et al ${ }^{66}$ \\
\hline Kiwi & $\begin{array}{l}\text { Lipid-Metabolism Regulation } \\
\text { - By improving plasma lipid levels } \\
\text { - By reducing TG levels in the blood } \\
\text { - By improving dietary lipid absorptions and reabsorptions, } \\
\text { as it also contains soluble fibre } \\
\text { Platelet-Inhibiting Functions } \\
\text { - By reducing platelet reactivity to collagen and ADP } \\
\text { - By inhibiting fibrinolysis activity } \\
\text { Blood Pressure Modulation } \\
\text { - By inhibiting ACE activity } \\
\text { - By decreasing diastolic and systolic blood pressures } \\
\text { Thrombosis Suppression } \\
\text { - By improving the efficacy of thrombosis prophylaxis } \\
\text { Reduction of Cholesterol Levels } \\
\text { - By inhibiting HMG-CoA reductase } \\
\text { - By improving apolipoprotein B/apolipoprotein AI ratio } \\
\text { - By improving plasma HDL-c and TC/HDL-c ratio } \\
\text { - By preventing atherosclerosis }\end{array}$ & $\begin{array}{l}\text { Duttaroy and Jørgensen, }{ }^{73} \text { Iwasawa et al, }{ }^{72} \text { Jung et al, }{ }^{76} \text { Karlsen et al, },{ }^{79} \text { Padmanabhan } \\
\text { and Paliyath, }{ }^{78} \text { Stonehouse et al }{ }^{74}\end{array}$ \\
\hline Pomegranate & $\begin{array}{l}\text { Lipid-Metabolism Regulation } \\
\text { - By reducing aortic sinus and coronary artery } \\
\text { atherosclerosis } \\
\text { - By reducing lipid peroxidation levels } \\
\text { Protection of Vascular Endothelial Function } \\
\text { - By reducing hypertension, coronary artery disease and } \\
\text { peripheral artery disease } \\
\text { Blood Pressure Modulation } \\
\text { - By reducing ACE activity } \\
\text { - By relieving hypertension } \\
\text { Ischemic or Reperfusion Reduction } \\
\text { - Reducing cellular ATP/ADP ratio in cardiomyocytes } \\
\text { Oxidative Stress Reduction } \\
\text { - By enhancing phase II enzyme activity in high-fibre diet- } \\
\text { induced cardiovascular disorders } \\
\text { - By giving strong antioxidant effects } \\
\text { - By increasing antioxidant defences } \\
\text { Inflammation Reduction } \\
\text { - Reducing arrhythmia } \\
\text { - By improving mitochondrial function in the } \\
\text { paraventricular nucleus } \\
\text { - By reducing Ca }{ }^{2+} \text { ATPase levels } \\
\text { Reduce Cholesterol Level } \\
\text { - By acting as atheroprotective }\end{array}$ & $\begin{array}{l}\text { Al-Jarallah et al, }{ }^{16}{ }^{16} \text { ao et al, }{ }^{85} \text { Haghighian et al, }{ }^{94} \text { Jadeja et al, }{ }^{90} \text { Mohan et al, }{ }^{83} \text { Shao } \\
\text { et al, }{ }^{93} \text { Sun et al, }{ }^{89} \text { Hajipour et al }{ }^{87}\end{array}$ \\
\hline
\end{tabular}

(Continued) 
Table 2 (Continued).

\begin{tabular}{|c|c|c|}
\hline $\begin{array}{l}\text { Nutritional } \\
\text { Fruits }\end{array}$ & Mechanism of Action & Reference \\
\hline Papaya & $\begin{array}{l}\text { Lipid-Metabolism Regulation } \\
\text { - By reducing fat absorption } \\
\text { - By treating lipid abnormalities at the prediabetic stage } \\
\text { - By preventing prediabetes patients from getting diabetes } \\
\text { mellitus type } 2 \\
\text { - By improving lipid profile } \\
\text { - By reducing triglyceride levels } \\
\text { Blood Pressure Modulation } \\
\text { - By reducing arterial blood pressure } \\
\text { - By having potent anti-hypertensive properties } \\
\text { - By inhibiting ACE activity } \\
\text { - By reducing cardiac hypertrophy } \\
\text { Oxidative Stress Reduction } \\
\text { - By ameliorating free radicals-induced damage } \\
\text { Inflammation Reduction } \\
\text { - By preventing heart attacks and strokes as well as } \\
\text { decreasing cholesterol levels } \\
\text { - By preventing morbidity and death }\end{array}$ & Brasil et al, ${ }^{100}$ Gayosso-García et al, ${ }^{97}$ Hiraga et al, ${ }^{98}$ Santana et al, ${ }^{95}$ Wilson et al ${ }^{96}$ \\
\hline Pineapple & $\begin{array}{l}\text { Platelet-Inhibiting Functions } \\
\text { - By performing fibrinolytic activity } \\
\text { Ischemic or Reperfusion Reduction } \\
\text { - Reducing ischemic conditions in the reperfusion of the } \\
\text { skeletal muscles. } \\
\text { Oxidative Stress Reduction } \\
\text { - By increasing antioxidant activity } \\
\text { Thrombosis Suppression } \\
\text { - By inhibiting blood platelet aggregation, minimising the } \\
\text { risks from having arterial thrombosis and embolism } \\
\text { - By reducing coagulation via the interference of fibrinogen } \\
\text { and facilitation of a good blood flow through the vessels } \\
\text { Inflammation Reduction } \\
\text { - By protecting cell membrane integrity } \\
\text { - By improving isoproterenol-induced cardiac systolic/ } \\
\text { diastolic dysfunction } \\
\text { - By reducing the degree of myocardial damage } \\
\text { Reduce Cholesterol Level } \\
\text { - By breaking down cholesterol plaques }\end{array}$ & Juhasz et al, ${ }^{108}$ Neumayer et al, ${ }^{153}$ Saxena and Panjwani, ${ }^{104}$ Wali ${ }^{102}$ \\
\hline Watermelon & $\begin{array}{l}\text { Lipid-Metabolism Regulation } \\
\text { - By reducing body weight, BMI and waist-to-hip ratio } \\
\text { Blood Pressure Modulation } \\
\text { - By reducing systolic blood pressure } \\
\text { - By improving vascular health in hypertensive patients } \\
\text { Oxidative Stress Reduction } \\
\text { - By increasing total antioxidant capacity } \\
\text { Reduce Cholesterol Level } \\
\text { - By reducing the levels of TG, LDL and TBARS } \\
\text { - By increasing HDL levels }\end{array}$ & Jumde and Shukla, ${ }^{113}$ Connolly et al, ${ }^{11 '}$ Shanely et al, ${ }^{112}$ WHO ${ }^{114}$ \\
\hline
\end{tabular}

Notes: All the abbreviations are available in the main text. 
Aortic aneurysm is a potentially deadly disorder that can result in death, especially if it ruptures. Overall, chronic inflammation, disruptive connective tissue remodeling and the loss of smooth muscle cells in the aortic wall are important factors in the development of aortic aneurysms. ${ }^{115}$ Studies have indicated that the development of aortic aneurysm is ameliorated by apple and pomegranate fruits. ${ }^{21,84,116}$

Atherosclerosis is a chronic and progressive artery disease caused by inflammatory responses, oxidative stress, lipid dysregulation and epigenetic disorders. ${ }^{117,118}$ The pathology of the disease is linked to other types of CVDs, including coronary artery disease, ischemic stroke, hypertension and peripheral arterial disease, which account for the majority of CVD-related deaths. ${ }^{119}$ Hyperlipidemia causes an increase in and deposition of ox-LDL in the sub-endothelial layer, promoting atherosclerosis progression. ${ }^{120}$ Apple, grapes, kiwi, pomegranate and watermelon fruits have high antioxidant potential, which decrease lipid peroxidation and the production of ox-LDL, as well as the inflammatory response and the progression of atherosclerosis. ${ }^{27,47,75,77,79,83,112,116}$

When the heart is exposed to a range of pro-hypetrophic stimuli, cardiac hypertrophy is recognized as an adaptive mechanism. ${ }^{121}$ Cardiac hypertrophy is characterized by increased in cardiomyocyte size and sarcomere intensity. On the other hand, sustained hypertrophy causes cardiac decompensation, contractile dysfunction and, as a result, heart failure. ${ }^{122}$ In cardiac hypertrophy and heart failure, papaya and pomegranate fruits have suppressive effects. ${ }^{84,100}$ Unlike chemotherapeutic drugs, isoproterenol is a non-selective $\beta$-adreno receptor agonist used in the treatment of bradycardia, heart block and asthma, with serious cardiac side effects. Isoproterenol causes ischemic damage to the heart as demonstrated by the increased heart rate, decreased $\mathrm{R}$ amplitude and ST elevation, as well as dysfunction in contractility. ${ }^{123}$ Mitochondrial damage, depletion of endogenous antioxidants and lysosomal activity all played important roles in conferring these effects.123,124 Pretreatments with mango, pineapple and pomegranate fruits increased antioxidant enzymes and protect against isoproterenol cardiotoxicity and cardiomyopathy. ${ }^{61,90,104}$

Cardiovascular problems such as diabetic cardiomyopathy, myocardial infarction and stroke, are the leading cause of diabetic-related death. ${ }^{125}$ In diabetic-induced animals, pomegranate, papaya and pineapple fruits decreased biomarkers of carbohydrate and lipid disturbances, implying a defensive function against diabetic complications and cardiovascular disorders. ${ }^{83,99,106,107}$

Myocardial infarction is more common in people who have an underlying atherosclerotic disorder involving hypertension, diabetes and dyslipidemia as risk factors. Rapid reperfusion and conventional medicine, such as $\beta$ blockers, mineralocorticoid receptor blockers, angiotensinconverting enzyme (ACE) inhibitors and statins, are commonly used to treat acute myocardial infarction. ${ }^{126}$ Additional medication is required to reduce infarct size, prevent arrhythmia and prevent progressive left ventricular (LV) remodeling, leading to heart failure. ${ }^{127}$ The antiinflammatory effects of mango and pineapple fruits can protect the heart from developing an infarct by reducing oxidative damage, which prevented reperfusion injury. ${ }^{61,104}$

Stroke, like myocardial infarction, is caused by vascular or microvascular disorders that cause an interruption of cerebral blood flow and, as a result, brain dysfunction. ${ }^{128}$ Apple, grapes and pineapple extracts have been shown to minimize the risk for stroke and neurobehavioral deficits by inhibiting the downregulation of antioxidant enzymes, which results in less development of ROS and oxidative stress, inhibition of lipid peroxidation, increased nitric oxide production and improved endothelial function in arteries. ${ }^{21,96,109}$ All these evidences indicated that nutritional fruits are multi-targeted with multiple therapeutic applications in CVDs (Figure 9).

Based on the literatures, the 10 selected nutritional fruits can regulate oxidative stress and exert positive influences on macrophage, endothelial cells, platelet function, lipid oxidation, blood glucose levels, lipid metabolism, vasodilatory effects and blood pressure through the inhibition of ACE activity, all of which are crucial in protecting the cardiovascular system. However, further pharmacological studies are required to determine the pharmacological potentials of these nutritional fruits. In the future, clinical trials will be needed to refine the nutritional fruits and their phytoconstituents into various pharmaceutical formulations while maintaining the quality and activity of bioactive constituents.

\section{Challenges and Opportunities of Nutritional Fruits-Based Formulations and Drug Delivery Methods for the Treatment of CVDs}

Natural products and their derivatives have been shown to confer significant therapeutic benefits where they account 


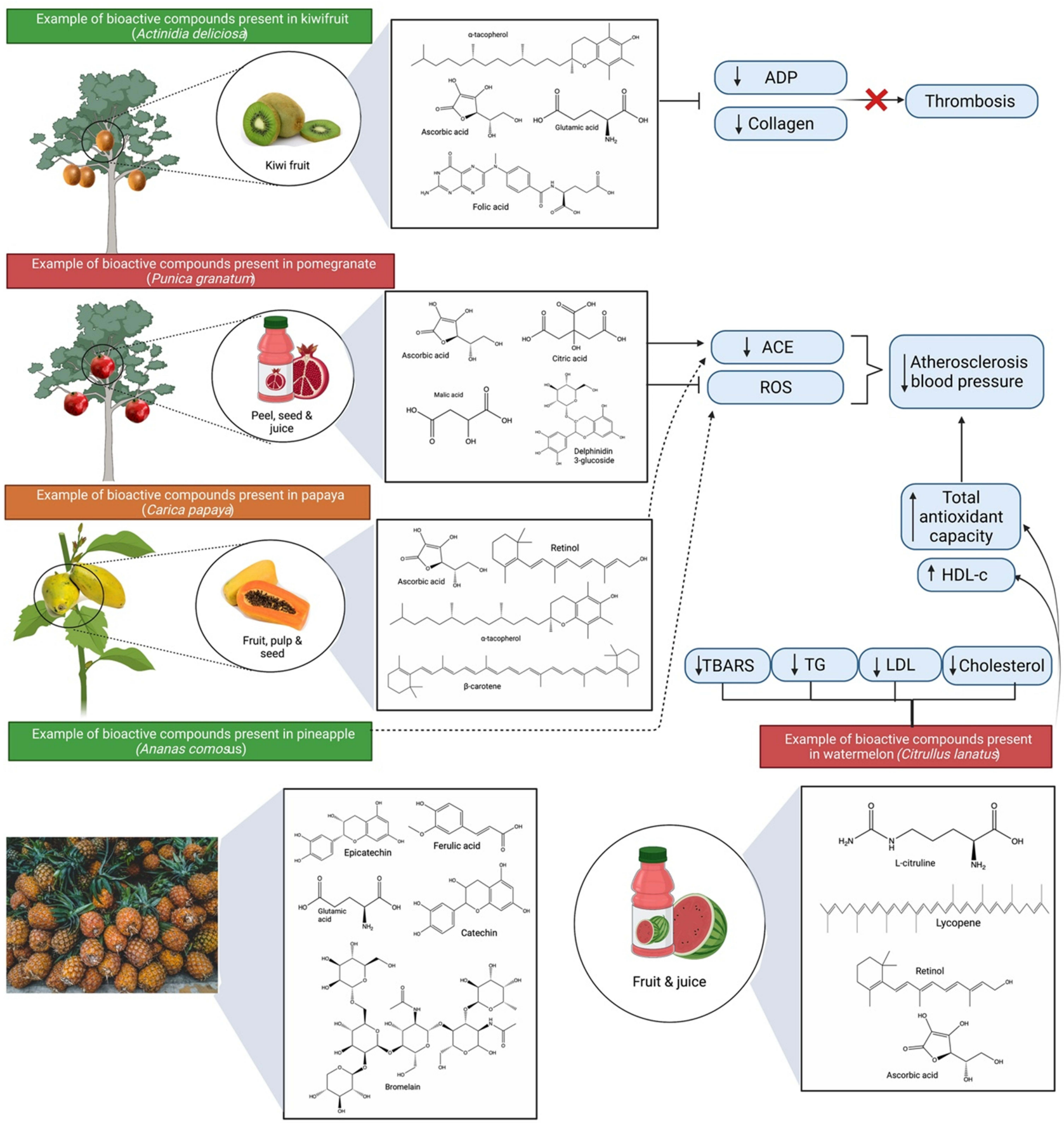

Figure 9 Bioactive compounds and protective effects of kiwifruit (Actinidia deliciosa), pomegranate (Punica granatum), papaya (Carica papaya), pineapple (Ananas comosus) and watermelon (Citrullus lanatus). The mechanism of action involves reduction of thrombosis, atherosclerosis and blood pressure via lowering platelets' responsiveness to collagen and ADP, reducing ACE activity, oxidative stress, inflammation and regulation of blood cholesterol levels.

Abbreviations: ADP, adenosine diphosphate; ACE, angiotensin-converting enzyme.

for approximately one-third of the top-selling pharmaceuticals. $^{129}$ Such products are favoured due to their unique characteristics, such as improved therapeutic efficacy, low/no adverse effects and relatively lower cost as compared to modern medicines. ${ }^{129}$ The favourable effects of natural product on cardiovascular risk have consistently been confirmed by a large piece of evidence where the opposite (insufficient intake of nutritious fruits) has been linked to an increased risk of CVD. The beneficial effects of consumption of nutritious fruits are dose-dependent. ${ }^{130}$

To date, fruits including apple, avocado, grape, mango, orange, kiwifruit, pomegranate, papaya, pineapple and 
watermelon have been extensively investigated and have been shown to confer protective effects on CVDs. Bioactive compounds obtained from fruits can help prevent CVDs or ameliorate the morphology and functions of blood vessels as well as the heart following an injury. Among the mechanisms involved are regulation of lipid metabolism, protection of vascular endothelial function, modulation of blood pressure, relief of ischemia/reperfusion injury, inhibition of platelet function, suppression of thrombosis, attenuation of inflammation and reduction of oxidative stress. $^{131}$

Various formulations including freeze-dried powder, extracts, juices, tablets and capsules have been designed and have shown to be effective against several CVDs. Grapes in various forms, including whole-grape powder, ${ }^{132}$ grape seed extract ${ }^{48,50}$ and tablet ${ }^{133}$ have shown good efficacy against various CVDs in experimental models including conferring vascular benefits, preventing atherosclerosis, reducing platelet reactivity and acting as antihypertensive.

However, due to biocompatibility and toxicity issues, it remains a challenge for many natural products to pass clinical studies ${ }^{129}$ due to 1 ) the development of insoluble complexes with other components present in the gastrointestinal tract (GIT), 2) low permeability across the epithelium cells or mucus layer, 3) limited release from the food matrix, 4) molecular transformations in the GIT, and 5) relatively low and/or variable oral bioavailability. The latter contributes to an incomplete absorption in the GIT as well as first-pass metabolism, which is the key research focus to date.

Vitamins, minerals, nutrients, and phenolic compounds are present in varying concentrations in almost all the nutritional fruits, and they are primarily responsible for preventing CVDs. However, key substances such as punicalagin from pomegranate, mangiferin from mango, volatile compounds from orange, procyanidin from kiwifruit, and lycopene from watermelon may also play a role in CVD protection. A compound that has good cardiovascular potential is punicalagin, a key component in pomegranate. ${ }^{85}$ Nevertheless, punicalagin has poor pharmacokinetic parameters including 1) low bioavailability, 2) ineffective absorption, 3) high metabolism, and 4) high systemic elimination. ${ }^{134,135}$ Therefore, designing a novel molecule for the treatment of CVDs such as punicalagin is advantageous.

Several therapeutic targets exist in the cardiovascular system, including ameliorating ischemic/reperfusion injury, myocardial infarction and atherosclerosis. Some novel technologies including chemicals and biologicals have been created for both targeted and prolonged delivery of novel therapeutics, making the field of specifically targeted drug delivery to the cardiovascular system a great potential. Nanomedicine is the way forward to bridge the gap between pharmaceutical constraints and natural phytochemical therapeutic potentials by enhancing compound targeting, pharmacokinetics, efficacy and cellular uptake. ${ }^{125,136-142}$

The use of nanoparticles in drug delivery such as polylactic-co-glycolic acid (PLGA), polyethylene glycol (PEG), liposomal delivery systems and RNA-based delivery offers several advantages including 1) improving ease of adsorption, 2) selective targeting, 3) simple encapsulation, 4) enhanced bioavailability, and 5) reduced adverse effects and 6) improved stability for CVDs. ${ }^{143}$ These new delivery systems offer many options for achieving tissue selectivity and reduced system exposure required to deploy new pharmacological compounds derived from nutritional fruits for better treatment of CVDs (Figure 10).

\section{Conclusion and Future Perspectives}

Overall, the present comprehensive review indicated that nutritional fruits have good cardioprotective properties. Additionally, several viewpoints on the use of nutritional fruits for cardioprotective potential, prevention and treatment have been proposed in this review. Furthermore, conducting additional research to understand the effect of nutritional fruits in the treatment of myocardial infarction, hypertension, peripheral artery disease, coronary artery disease, cardiomyopathies, dyslipidemias, ischemic stroke, aortic aneurysm, atherosclerosis, cardiac hypertrophy and heart failure, diabetic cardiovascular complications, drug-induced cardiotoxicity and cardiomyopathy are also required. Although nutritional fruits have many therapeutic potentials against CVDs, the majority are still in the phase of preclinical research in which randomised controlled trials can help support the preclinical findings. As the pathology and risk factors that lead to the onset of CVDs are broad, determining new effective drugs become a challenge. However, further pathways and targets of each active ingredient either when used singly or in various combinations must be investigated in order to elucidate the mechanism of action of nutritional fruits. It is also important to determine a good starting point for the development of a pharmacological model based on multiple omics studies including genomics, proteomics and metabolomics. 


\section{Example of bioactive compounds for treatment of atherosclerosis}

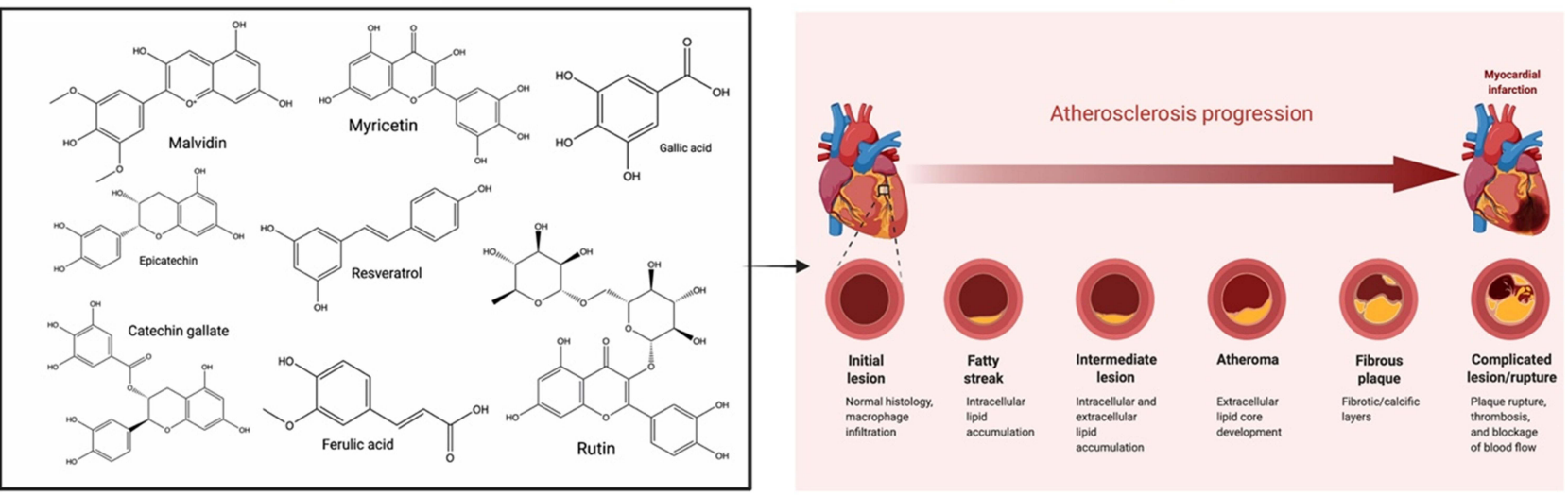

Example of drug delivery strategies use in cardiovascular diseases (CVDs)

Proposed future perspectives by employing liposomes
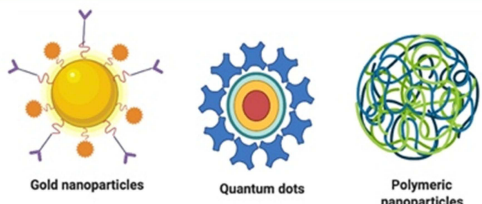

Polymeric
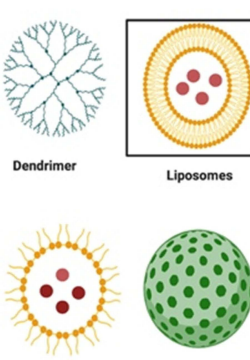

Mesoporous silica
nanoparticles

Carbon nanotube
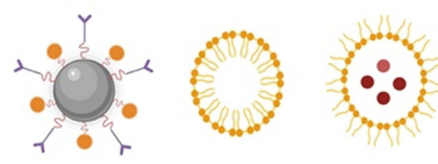

Magnetic
nanoparticles

Micelles
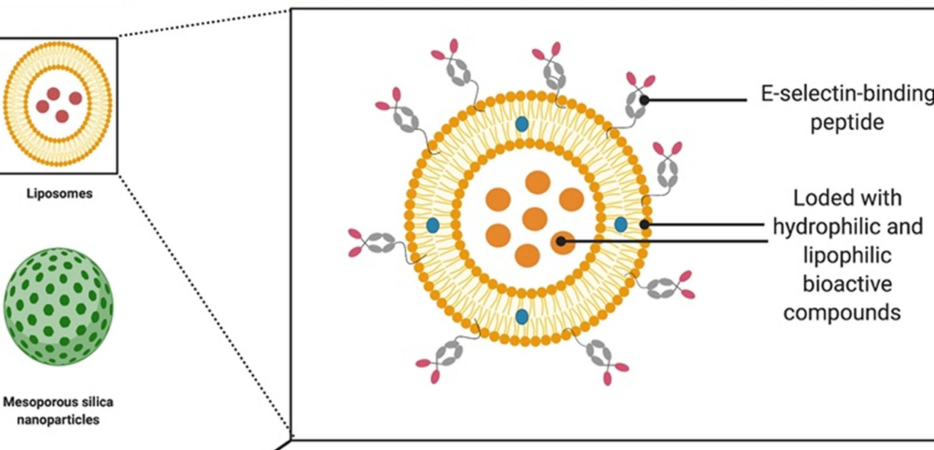

ifor

$\downarrow$ E

Endocytosis
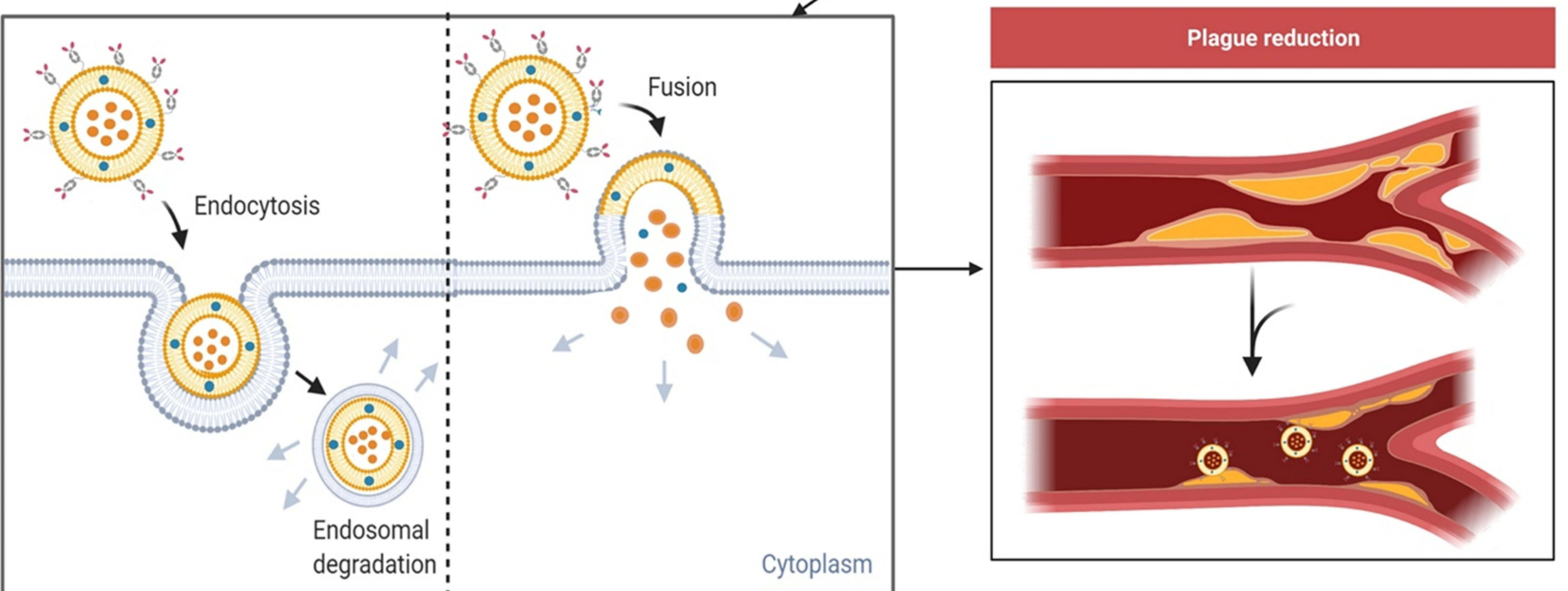

Figure 10 Drug delivery strategies use in cardiovascular diseases (CVDs) and proposed future perspectives of liposomes-based drug delivery. Atherosclerosis began as a lesion before a lipid layer or fatty streak formed within the intima. Leukocytes and smooth muscle cells migrate into the arterial wall, causing plague and extracellular matrix degradation. Liposomes can be loaded with hydrophilic and lipophilic bioactive substances, which may help decrease plague development. Injured endothelium secretes adhesion molecules during atherosclerosis, thus liposomes can be modified to conjugate with E-selectin-binding peptide (eg, E-selectin, and P-selectin). This combination of bioactive molecules and targeted ligands will further aid in decreasing atherosclerosis.

This review discovered a link between eating nutritional fruits and having a healthier heart. Include at least 1 of the 10 nutritional fruits listed in this review as your daily diet to lower your risk of CVDs. Pomegranate and grapes have been well explored and the mechanism of action is well documented against 
CVDs, compared to other nutritional fruits. All of the fruits mentioned are edible and readily accessible on the market. Consuming these fruits, which may contain varying amounts of active constituents depending on the food source and season, the development of nutritious fruits-based health supplements would be more realistic for consistent CVD protection. However, studies on other nutritional fruits are advocated to be used as a dietary supplement for the prevention and treatment of CVDs, thereby representing a complementary non-pharmacological therapy for CVDs, based on the overall positive results of various preclinical and clinical trials. Determining the exact mechanism of action for the active constituents can help understand not only how the different ingredients in nutritional fruits work singly or in combination but also lead to the discovery of new pathways or synergistic effects. Thus, future perspectives will be refocusing on the development of new drugs capable of treating various aspects of CVD, as well as making nutritional fruits as a crucial source of pharmaceuticals.

\section{Acknowledgments}

The authors appreciate the Universiti Kuala Lumpur Royal College of Medicine Perak, Ipoh, Perak, Malaysia, for providing the facilities and services required to complete the study. The figures and graphical abstract in this manuscript were created with BioRender.com and the support of https://biorender.com under a paid subscription.

\section{Author Contributions}

N.Z.A.Z. and M.S. conceived the idea, designed, collected the literature, conducted the study, interpreted the data, analysed the data, drafted and revised the manuscript. All authors have made noteworthy contributions to the study design, data collection, review and interpretation; have engaged in the drafting or revision of the article; have agreed to submit to the current journal; have given final approval of the version to be published; and have agreed to be responsible for all aspects of the works.

\section{Funding}

There is no funding to report.

\section{Disclosure}

The authors report no conflicts of interest in this work.

\section{References}

1. Mc Namara K, Alzubaidi H, Jackson JK. Cardiovascular disease as a leading cause of death: how are pharmacists getting involved? Int Pharm Res Pract. 2019;8:1. doi:10.2147/IPRP. S133 088

2. Lin JS, Evans CV, Johnson E, Redmond N, Coppola EL, Smith N. Nontraditional risk factors in cardiovascular disease risk assessment: updated evidence report and systematic review for the US Preventive Services Task Force. JAMA. 2018;320(3):281-297. doi:10.1001/jama.2018.4242

3. Weinhaus AJ, Roberts KP. Anatomy of the Human Heart. In: Iaizzo PA, editor. Handbook of Cardiac Anatomy, Physiology, and Devices: Second Edition. Totowa, NJ: Humana Press; 2005:59-85.

4. Mesotten L, Maes A, Hambÿe A-S, et al. Nuclear cardiology, Part I: anatomy and function of the normal heart. J Nucl Med Technol. 1998;26(1):4-8.

5. Kadoya K, Kaneko S Modeling of a cardiovascular system to investigate factors affecting hypertension. 2018 12th International Symposium on Medical Information and Communication Technology (ISMICT): IEEE; 2018:1-6.

6. Hughson RL, Helm A, Durante M. Heart in space: effect of the extraterrestrial environment on the cardiovascular system. Nat Rev Cardiol. 2018;15(3):167-180. doi:10.1038/nrcardio.2017.157

7. Rehan F, Qadeer A, Bashir I, Jamshaid M. Risk factors of cardiovascular disease in developing countries. Int Curr Pharm J. 2016;5(8):69-72. doi:10.3329/icpj.v5i8.28875

8. Ng SW, Norton EC, Popkin BM. Why have physical activity levels declined among Chinese adults? Findings from the 1991-2006 China Health and Nutrition Surveys. Soc Sci Med. 2009;68(7):1305-1314. doi:10.1016/j.socscimed.2009.01.035

9. Fernández MG, Marset JB, Lesmes IB, et al. FESNAD-SEEDO consensus summary: evidence-based nutritional recommendations for the prevention and treatment of overweight and obesity in adults. Endocrinol y Nutr. 2012;59(7):429-437. doi:10.1016/j. endoen.2012.08.009

10. Amine E, Baba N, Belhadj M, et al. Diet, nutrition and the prevention of chronic diseases. World Health Organization technical report series. 2003(916).

11. Everson-Rose SA, Lewis TT. Psychosocial factors and cardiovascular diseases. Annu Rev Public Health. 2005;26:469-500. doi:10.1146/annurev.publhealth.26.021304.144542

12. Liu RH. Health-promoting components of fruits and vegetables in the diet. Advan Nutri. 2013;4(3):384S-392S. doi:10.3945/ an. 112.003517

13. Willett WC. Balancing life-style and genomics research for disease prevention. Science. 2002;296(5568):695-698. doi:10.1126/ science. 1071055

14. Sharifi-Rad J, Rodrigues CF, Sharopov F, et al. Diet, lifestyle and cardiovascular diseases: linking pathophysiology to cardioprotective effects of natural bioactive compounds. Int $J$ Environ Res Public Health. 2020;17(7):2326. doi:10.3390/ijerph17072326

15. Anand SS, Hawkes C, De Souza RJ, et al. Food consumption and its impact on cardiovascular disease: importance of solutions focused on the globalized food system: a report from the workshop convened by the World Heart Federation. J Am Coll Cardiol. 2015;66(14):1590-1614.

16. Cocchi C, Coppi F, Farinetti A, Mattioli AV. Cardiovascular disease prevention and therapy in women with Type 2 diabetes. Future Cardiol. 2021;17(3):487-496. doi:10.2217/fca-2021-0011

17. Humphries KH, Izadnegadar M, Sedlak T, et al. Sex differences in cardiovascular disease-impact on care and outcomes. Front Neuroendocrinol. 2017;46:46. 
18. Mattioli AV, Francesca C, Mario M, Alberto F. Fruit and vegetables in hypertensive women with asymptomatic peripheral arterial disease. Clin Nutri ESPEN. 2018;27:110-112. doi:10.1016/j. clnesp.2018.05.010

19. Chen C-Y, Milbury PE, Lapsley K, Blumberg JB. Flavonoids from almond skins are bioavailable and act synergistically with vitamins $\mathrm{C}$ and $\mathrm{E}$ to enhance hamster and human LDL resistance to oxidation. J Nutr. 2005;135(6):1366-1373. doi:10.1093/jn/135.6.1366

20. Hattori Y, Jojima T, Tomizawa A, et al. A glucagon-like peptide-1 (GLP-1) analogue, liraglutide, upregulates nitric oxide production and exerts anti-inflammatory action in endothelial cells (Retraction of vol 53, pg 2256, 2010). DIABETOLOGIA. 2012;55(2):533. doi:10.1007/s00125-011-2394-z

21. Sandoval-Ramírez BA, Catalán Ú, Calderón-Pérez L, et al. The effects and associations of whole-apple intake on diverse cardiovascular risk factors. A narrative review. Crit Rev Food Sci Nutr. 2020;60(22):3862-3875. doi:10.1080/10408398.2019.1709801

22. Hodgson JM, Prince RL, Woodman RJ, et al. Apple intake is inversely associated with all-cause and disease-specific mortality in elderly women. Br J Nutri. 2016;115(5):860-867. doi:10.1017/ S0007114515005231

23. Bondonno NP, Bondonno CP, Blekkenhorst LC, et al. Flavonoidrich apple improves endothelial function in individuals at risk for cardiovascular disease: a randomized controlled clinical trial. $\mathrm{Mol}$ Nutr Food Res. 2018;62(3):1700674. doi:10.1002/mnfr.201700674

24. Gayer BA, Avendano EE, Edelson E, Nirmala N, Johnson EJ, Raman G. Effects of intake of apples, pears, or their products on cardiometabolic risk factors and clinical outcomes: a systematic review and meta-Analysis. Curr Develop Nutri. 2019;3(10): nzz109. doi:10.1093/cdn/nzz109

25. Ravn-Haren G, Dragsted LO, Buch-Andersen T, et al. Intake of whole apples or clear apple juice has contrasting effects on plasma lipids in healthy volunteers. Eur J Nutr. 2013;52 (8):1875-1889. doi:10.1007/s00394-012-0489-z

26. Koutsos A, Tuohy KM, Lovegrove JA. Apples and cardiovascular health - is the gut microbiota a core consideration? Nutrients. 2015;7(6):3959-3998. doi:10.3390/nu7063959

27. Tian J, Wu X, Zhang M, Zhou Z, Liu Y. Comparative study on the effects of apple peel polyphenols and apple flesh polyphenols on cardiovascular risk factors in mice. Clin Exp Hypertens. 2018;40 (1):65-72. doi:10.1080/10641963.2017.1313851

28. D'Angelo S, La Porta R, Napolitano M, Galletti P, Quagliuolo L, Boccellino M. Effect of Annurca apple polyphenols on human HaCaT keratinocytes proliferation. $J$ Med Food. 2012;15 (11):1024-1031. doi:10.1089/jmf.2012.0076

29. Serra AT, Rocha J, Sepodes B, et al. Evaluation of cardiovascular protective effect of different apple varieties-correlation of response with composition. Food Chem. 2012;135(4):23782386. doi:10.1016/j.foodchem.2012.07.067

30. Gonzalez J, Donoso W, Sandoval N, et al. Apple peel supplemented diet reduces parameters of metabolic syndrome and atherogenic progression in ApoE-/- mice. Evid Based Compl AlternMed. 2015;2015:1-10. doi:10.1155/2015/918384

31. Balasuriya N, Rupasinghe HV. Antihypertensive properties of flavonoid-rich apple peel extract. Food Chem. 2012;135 (4):2320-2325. doi:10.1016/j.foodchem.2012.07.023

32. Mahmassani HA, Avendano EE, Raman G, Johnson EJ. Avocado consumption and risk factors for heart disease: a systematic review and meta-analysis. Am J Clin Nutr. 2018;107(4):523536. doi:10.1093/ajen/nqx078

33. Carvajal-Zarrabal O, Nolasco-Hipolito C, Aguilar-Uscanga MG, Melo-Santiesteban G, Hayward-Jones PM, Barradas-Dermitz DM. Avocado oil supplementation modifies cardiovascular risk profile markers in a rat model of sucrose-induced metabolic changes. Dis Markers. 2014;2014:1-8. doi:10.1155/2014/386425
34. Sousa FH, Valenti VE, Pereira LC, et al. Avocado (Persea americana) pulp improves cardiovascular and autonomic recovery following submaximal running: a crossover, randomized, double-blind and placebo-controlled trial. Sci Rep. 2020;10(1):1-12. doi:10.1038/s41598-020-67577-3

35. Null G, Pennesi L, Feldman M. Nutrition and lifestyle intervention on mood and neurological disorders. J Evid Based Complementary Altern Med. 2017;22(1):68-74. doi:10.1177/ 2156587216637539

36. Park E, Edirisinghe I, Burton-Freeman B. Avocado fruit on postprandial markers of cardio-metabolic risk: a randomized controlled dose response trial in overweight and obese men and women. Nutrients. 2018;10(9):1287. doi:10.3390/nu10091287

37. Neboh E, Ufelle S, Anele T. Effect of methanolic seed extract of (Avocado Pear) on prothrombin time and activated partial thromboplastin time in mice. $J$ Exp Res. 2015;3(2):92-96.

38. Rodriguez-Sanchez DG, Flores-García M, Silva-Platas C, et al. Isolation and chemical identification of lipid derivatives from avocado (Persea americana) pulp with antiplatelet and antithrombotic activities. Food Funct. 2015;6(1):192-202. doi:10.1039/C4FO00610K

39. Gouegni E, Abubakar H. Phytochemical, toxicological, biochemical and haematological studies on avocado (Persea americana) in experimental animals. Nigerian Food J. 2013;31(1):64-69. doi:10.1016/S0189-7241(15)30057-6

40. Dabas D, Shegog M, Ziegler G, Lambert J. Avocado (Persea americana) seed as a source of bioactive phytochemicals. Curr Pharm Des. 2013;19(34):6133-6140. doi:10.2174/1381612811319340007

41. Šikuten I, Štambuk P, Andabaka Ž, et al. Grapevine as a rich source of polyphenolic compounds. Molecules. 2020;25 (23):5604. doi:10.3390/molecules25235604

42. Manach C, Scalbert A, Morand C, Rémésy C, Jiménez L. Polyphenols: food sources and bioavailability. Am J Clin Nutr. 2004;79(5):727-747.

43. Wightman JD, Heuberger RA. Effect of grape and other berries on cardiovascular health. J Sci Food Agric. 2015;95(8):15841597. doi:10.1002/jsfa. 6890

44. Safwen K, Selima S, Mohamed E, et al. Protective effect of grape seed and skin extract on cerebral ischemia in rat: implication of transition metals. Int J Stroke. 2015;10(3):415-424. doi:10.1111/ ijs. 12391

45. Shanmuganayagam D, Beahm MR, Kuhns MA, Krueger CG, Reed JD, Folts JD. Differential effects of grape (Vitis vinifera) skin polyphenolics on human platelet aggregation and low-density lipoprotein oxidation. J Agri Food Chem. 2012;60(23):57875794. doi:10.1021/jf203487g

46. MacMahon S, Duffy S, Rodgers A, et al. Blood cholesterol and vascular mortality by age, sex, and blood pressure: a meta-analysis of individual data from 61 prospective studies with 55000 vascular deaths. Lancet. 2007;370(9602):1829-1839.

47. Brown BG, Stukovsky KH, Zhao X-Q. Simultaneous low-density lipoprotein-C lowering and high-density lipoprotein-C elevation for optimum cardiovascular disease prevention with various drug classes, and their combinations: a meta-analysis of 23 randomized lipid trials. Curr Opin Lipidol. 2006;17(6):631-636. doi:10.1097/ MOL.0b013e32800ff750

48. Razavi S-M, Gholamin S, Eskandari A, et al. Red grape seed extract improves lipid profiles and decreases oxidized low-density lipoprotein in patients with mild hyperlipidemia. $J$ Med Food. 2013;16(3):255-258. doi:10.1089/jmf.2012.2408

49. Leibowitz A, Faltin Z, Perl A, et al. Red grape berry-cultured cells reduce blood pressure in rats with metabolic-like syndrome. Eur J Nutr. 2014;53(3):973-980. doi:10.1007/s00394-013-0601-z

50. Luzak B, Kosiorek A, Syska K, et al. Does grape seed extract potentiate the inhibition of platelet reactivity in the presence of endothelial cells? Adv Med Sci. 2014;59(2):178-182. doi:10.1016/j.advms.2014.02.005 
51. Resende AC, Emiliano AF, Cordeiro VS, et al. Grape skin extract protects against programmed changes in the adult rat offspring caused by maternal high-fat diet during lactation. J Nutr Biochem. 2013;24(12):2119-2126. doi:10.1016/j.jnutbio.2013.08.003

52. Quiñones M, Guerrero L, Suarez M, et al. Low-molecular procyanidin rich grape seed extract exerts antihypertensive effect in males spontaneously hypertensive rats. Food Res Int. 2013;51 (2):587-595. doi:10.1016/j.foodres.2013.01.023

53. Borde P, Mohan M, Kasture S. Effect of myricetin on deoxycorticosterone acetate (DOCA)-salt-hypertensive rats. Nat Prod Res. 2011;25(16):1549-1559. doi:10.1080/14786410903335190

54. Godse S, Mohan M, Kasture V, Kasture S. Effect of myricetin on blood pressure and metabolic alterations in fructose hypertensive rats. Pharm Biol. 2010;48(5):494 498. doi:10.3109/13880200903188526

55. Quintieri AM, Baldino N, Filice E, et al. Malvidin, a red wine polyphenol, modulates mammalian myocardial and coronary performance and protects the heart against ischemia/reperfusion injury. J Nutr Biochem. 2013;24(7):1221-1231. doi:10.1016/j. jnutbio.2012.09.006

56. Dohadwala MM, Vita JA. Grapes and cardiovascular disease. $J$ Nutr. 2009;139(9):1788S-1793S. doi:10.3945/jn.109.107474

57. Leifert WR, Abeywardena MY. Cardioprotective actions of grape polyphenols. Nutri Res. 2008;28(11):729-737. doi:10.1016/j. nutres.2008.08.007

58. Maldonado-Celis ME, Yahia EM, Bedoya R, et al. Chemical composition of Mango (Mangifera indica L.) fruit: nutritional and phytochemical compounds. Front Plant Sci. 2019;10:1073. doi:10.3389/fpls.2019.01073

59. Abbasi AM, Guo X, Fu X, et al. Comparative assessment of phenolic content and in vitro antioxidant capacity in the pulp and peel of Mango cultivars. Int J Mol Sci. 2015;16(6):1350713527. doi:10.3390/ijms160613507

60. Fidrianny I, Rahmiyani I, Wirasutisna KR. Antioxidant capacities from various leaves extracts of four varieties mangoes using DPPH, ABTS assays and correlation with total phenolic, flavonoid, carotenoid. Int J Pharm Pharm Sci. 2013;5(4):189-194.

61. Prabhu S, Jainu M, Sabitha KE, Devi CS. Cardioprotective effect of mangiferin on isoproterenol induced myocardial infarction in rats. Indian J Exp Biol. 2006;44(3):209-15.

62. Lobo V, Patil A, Phatak A, Chandra N. Free radicals, antioxidants and functional foods: impact on human health. Pharmacogn Rev. 2010;4(8):118. doi:10.4103/0973-7847.70902

63. Aptekmann NP, Cesar TB. Long-term Orange juice consumption is associated with low LDL-cholesterol and apolipoprotein B in normal and moderately hypercholesterolemic subjects. Lipids Health Dis. 2013;12(1):1-10. doi:10.1186/1476-511X-12-119

64. Ademosun AO, Oboh G. Effect of pineapple, Orange and watermelon juices on phosphodiesterase, monoamine oxidase and angiotensin-I converting enzyme activities in rat heart and brain homogenates. Orient Pharm Exp Med. 2017;17(3):269-276. doi:10.1007/s13596-017-0279-5

65. Asgary S, Keshvari M. Effects of citrus sinensis juice on blood pressure. ARYA Atheroscler. 2013;9(1):98.

66. Castello F, Fernández-Pachón M-S, Cerrillo I, et al. Absorption, metabolism, and excretion of Orange juice (poly) phenols in humans: the effect of a controlled alcoholic fermentation. Arch Biochem Biophys. 2020;695:108627. doi:10.1016/j.abb.2020.108627

67. Escudero-López B, Cerrillo I, Herrero-Martín G, et al. Fermented Orange juice: source of higher carotenoid and flavanone contents. J Agric Food Chem. 2013;61(37):8773-8782. doi:10.1021/ jf401240p

68. Del Rio D, Rodriguez-Mateos A, Spencer JP, Tognolini M, Borges G, Crozier A. Dietary (poly) phenolics in human health: structures, bioavailability, and evidence of protective effects against chronic diseases. Antioxid Redox Signal. 2013;18 (14):1818-1892. doi:10.1089/ars.2012.4581
69. Gattuso G, Barreca D, Gargiulli C, Leuzzi U, Caristi C. Flavonoid composition of citrus juices. Molecules. 2007;12(8):1641-1673. doi:10.3390/12081641

70. Drummond L. The composition and nutritional value of kiwifruit. Adv Food Nutr Res. 2013;68:33-57.

71. Ru J, Li P, Wang J, et al. TCMSP: a database of systems pharmacology for drug discovery from herbal medicines. $J$ Cheminform. 2014;6(1):1-6. doi:10.1186/1758-2946-6-13

72. Iwasawa H, Morita E, Yui S, Yamazaki M. Anti-oxidant effects of kiwi fruit in vitro and in vivo. Biol Pharm Bull. 2011;34(1):128134. doi: $10.1248 / \mathrm{bpb} .34 .128$

73. Duttaroy AK, Jørgensen A. Effects of kiwi fruit consumption on platelet aggregation and plasma lipids in healthy human volunteers. Platelets. 2004;15(5):287-292. doi:10.1080/ 09537100410001710290

74. Stonehouse W, Gammon CS, Beck KL, Conlon CA, von Hurst PR, Kruger R. Kiwifruit: our daily prescription for health. Can J Physiol Pharmacol. 2013;91(6):442-447. doi:10.1139/cjpp-2012-0303

75. Gammon CS, Kruger R, Minihane AM, Conlon CA, von Hurst PR, Stonehouse W. Kiwifruit consumption favourably affects plasma lipids in a randomised controlled trial in hypercholesterolaemic men. Br J Nutri. 2013;109(12):2208-2218. doi:10.1017/ S0007114512004400

76. Jung K-A, Song T-C, Han D, Kim I-H, Kim Y-E, Lee C-H. Cardiovascular protective properties of kiwifruit extracts in vitro. Biol Pharm Bull. 2005;28(9):1782-1785. doi:10.1248/ bpb.28.1782

77. Svendsen M, Tonstad S, Heggen E, et al. The effect of kiwifruit consumption on blood pressure in subjects with moderately elevated blood pressure: a randomized, controlled study. Blood Press. 2015;24(1):48-54. doi:10.3109/08037051.2014.976979

78. Padmanabhan P, Paliyath G. Kiwifruit. In: Caballero B, Finglas PM, Toldrá F, editors. Encyclopedia of Food and Health. Oxford, UK: Academic Press; 2016:490-494.

79. Karlsen A, Svendsen M, Seljeflot I, et al. Kiwifruit decreases blood pressure and whole-blood platelet aggregation in male smokers. $J$ Hum Hypertens. 2013;27(2):126-130. doi:10.1038/jhh.2011.116

80. Aune D, Giovannucci E, Boffetta P, et al. Fruit and vegetable intake and the risk of cardiovascular disease, total cancer and allcause mortality - a systematic review and dose-response metaanalysis of prospective studies. Int $J$ Epidemiol. 2017;46 (3):1029-1056. doi:10.1093/ije/dyw319

81. Zino S, Skeaff M, Williams S, Mann J. Randomised controlled trial of effect of fruit and vegetable consumption on plasma concentrations of lipids and antioxidants. BMJ. 1997;314 (7097):1787. doi:10.1136/bmj.314.7097.1787

82. Hsieh CL, Huang SM, Chen LI, Yu CM, Wong CH, Peng RY. Novel approach of using nutraceutic-directed caloric antioxidant density and ion-ratio for evaluating fruit's health quality. J Food Sci. 2016;81(8):H2059-H2068. doi:10.1111/1750-3841.13390

83. Mohan M, Waghulde H, Kasture S. Effect of pomegranate juice on Angiotensin II-induced hypertension in diabetic Wistar rats. Phytother Res. 2010;24(S2):S196-S203. doi:10.1002/ptr.3090

84. Al Hariri M, Zibara K, Farhat W, et al. Cigarette smoking-induced cardiac hypertrophy, vascular inflammation and injury are attenuated by antioxidant supplementation in an animal model. Front Pharmacol. 2016;7:397. doi:10.3389/fphar.2016.00397

85. Cao K, Xu J, Pu W, et al. Punicalagin, an active component in pomegranate, ameliorates cardiac mitochondrial impairment in obese rats via AMPK activation. Sci Rep. 2015;5(1):1-12. doi:10.1038/srep14014

86. Singh M, Jha A, Kumar A, Hettiarachchy N, Rai AK, Sharma D. Influence of the solvents on the extraction of major phenolic compounds (punicalagin, ellagic acid and gallic acid) and their antioxidant activities in pomegranate aril. J Food Sci Technol. 2014;51(9):2070-2077. doi:10.1007/s13197-014-1267-0 
87. Hajipour S, Sarkaki A, Mohammad S, Mansouri T, Pilevarian A, RafieiRad M. Motor and cognitive deficits due to permanent cerebral hypoperfusion/ischemia improve by pomegranate seed extract in rats. Pak J Biol Sci. 2014;17(8):991-998. doi:10.3923/ pjbs.2014.991.998

88. Ndisang JF, Vannacci A, Rastogi S. Oxidative Stress and Inflammation in Obesity, Diabetes, Hypertension, and Related Cardiometabolic Complications. Hindawi; 2014.

89. Sun W, Yan C, Frost B, et al. Pomegranate extract decreases oxidative stress and alleviates mitochondrial impairment by activating AMPK-Nrf2 in hypothalamic paraventricular nucleus of spontaneously hypertensive rats. Sci Rep. 2016;6(1):1-12.

90. Jadeja RN, Thounaojam MC, Patel DK, Devkar RV, Ramachandran A. Pomegranate (Punica granatum L.) juice supplementation attenuates isoproterenol-induced cardiac necrosis in rats. Cardiovasc Toxicol. 2010;10(3):174-180. doi:10.1007/ s12012-010-9076-9

91. Muthulakshmi S, Saravanan R. Protective effects of azelaic acid against high-fat diet-induced oxidative stress in liver, kidney and heart of C57BL/6J mice. Mol Cell Biochem. 2013;377(1):23-33. doi:10.1007/s11010-013-1566-1

92. Niemann B, Chen Y, Teschner M, Li L, Silber R-E, Rohrbach S. Obesity induces signs of premature cardiac aging in younger patients: the role of mitochondria. J Am Coll Cardiol. 2011;57 (5):577-585. doi:10.1016/j.jacc.2010.09.040

93. Shao D, Oka S-I, Liu T, et al. A redox-dependent mechanism for regulation of AMPK activation by Thioredoxin1 during energy starvation. Cell Metab. 2014;19(2):232-245. doi:10.1016/j. cmet.2013.12.013

94. Haghighian MK, Rafraf M, Moghaddam A, Hemmati S, Jafarabadi MA, Gargari BP. Pomegranate (Punica granatum L.) peel hydro alcoholic extract ameliorates cardiovascular risk factors in obese women with dyslipidemia: a double blind, randomized, placebo controlled pilot study. Eur J Integr Med. 2016;8 (5):676-682. doi:10.1016/j.eujim.2016.06.010

95. Santana LF, Inada AC, Espirito Santo BLSD, et al. Nutraceutical potential of Carica papaya in metabolic syndrome. Nutrients. 2019;11(7):1608. doi:10.3390/nu11071608

96. Wilson RK, Kwan TK, Kwan C-Y, Sorger GJ. Effects of papaya seed extract and benzyl isothiocyanate on vascular contraction. Life Sci. 2002;71(5):497-507. doi:10.1016/S0024-3205(02) 01708-3

97. Gayosso-García S, Yahia EM, Martínez-Téllez MA, GonzálezAguilar GA. Effect of maturity stage of papaya maradol on physiological and biochemical parameters. Am J Agri Biol Sci. 2010;5(2):194-203. doi:10.3844/ajabssp.2010.194.203

98. Hiraga Y, Ara T, Sato N, et al. Metabolic analysis of unripe papaya (Carica papaya L.) to promote its utilization as a functional food. Biosci Biotechnol Biochem. 2021;85(5):1194-1204. doi:10.1093/bbb/zbab014

99. Eno A, Owo O, Itam E, Konya R. Blood pressure depression by the fruit juice of Carica papaya (L.) in renal and DOCA-induced hypertension in the rat. Phytother Res. 2000;14(4):235-239. doi:10.1002/ 1099-1573(200006)14:4<235::AID-PTR574>3.0.CO;2-G

100. Brasil GA, Ronchi SN, Do Nascimento AM, et al. Antihypertensive effect of Carica papaya via a reduction in ACE activity and improved baroreflex. Planta Med. 2014;80 (17):1580-1587. doi:10.1055/s-0034-1383122

101. Seenak P, Kumphune S, Malakul W, Chotima R, Nernpermpisooth N. Pineapple consumption reduced cardiac oxidative stress and inflammation in high cholesterol diet-fed rats. Nutr Metab. 2021;18(1):1-10. doi:10.1186/s12986-021-00566-Z

102. Wali N. Chapter 3.34 - Pineapple (Ananas comosus). In: Nabavi SM, Silva AS, editors. Nonvitamin and Nonmineral Nutritional Supplements. Cambridge, MA, USA: Academic Press; 2019:367-373.
103. Heinicke R, Gortner W. Stem bromelain - a new protease preparation from pineapple plants. Econ Bot. 1957;11(3):225-234. doi:10.1007/BF02860437

104. Saxena P, Panjwani D. Cardioprotective potential of hydro-alcoholic fruit extract of Ananas comosus against isoproterenol induced myocardial infraction in Wistar Albino rats. $J$ Acute Dis. 2014;3(3):228-234. doi:10.1016/S2221-6189(14)60051-2

105. Livio M, Bertoni M, DeGaetano G. Effect of bromelain on fibrinogen level, prothrombin complex factors and platelet aggregation in the rat: a preliminary report. Drugs Exp Clin Res. 1978;4:49.

106. Gläser D, Hilberg T. The influence of bromelain on platelet count and platelet activity in vitro. Platelets. 2006;17(1):37-41. doi:10.1080/09537100500197489

107. Norred CL, Brinker F. Potential coagulation effects of preoperative complementary and alternative medicines. Altern Ther Health Med. 2001;7(6):58.

108. Juhasz B, Thirunavukkarasu M, Pant R, et al. Bromelain induces cardioprotection against ischemia-reperfusion injury through Akt/ FOXO pathway in rat myocardium. Am J Physiol Heart Circul Physiol. 2008;294(3):H1365-H1370. doi:10.1152/ ajpheart.01005.2007

109. Go AS, Mozaffarian D, Roger VL, et al. Heart disease and stroke statistics-2013 update: a report from the American Heart Association. Circulation. 2013;127(1). e6-e245.

110. Maoto MM, Beswa D, Jideani AI. Watermelon as a potential fruit snack. Int J Food Prop. 2019;22(1):355-370. doi:10.1080/ 10942912.2019.1584212

111. Connolly M, Lum T, Marx A, et al. Effect of fresh watermelon consumption on risk factors for cardiovascular disease in overweight and obese adults (P06-102-19). Curr Develop Nutri. 2019;3 (Supplement_1):nzz031. doi:10.1093/cdn/nzz031.P06-102-19

112. Shanely RA, Zwetsloot JJ, Jurrissen TJ, et al. Daily watermelon consumption decreases plasma sVCAM-1 levels in overweight and obese postmenopausal women. Nutri Res. 2020;76:9-19. doi:10.1016/j.nutres.2020.02.005

113. Jumde A, Gousoddin SR. Development and chemical analysis of watermelon blends with beetroot juice during storage. Int $J$ Sci Eng Technol. 2015;4:2395-4752.

114. WHO. Increasing Fruits and Vegetable Consumption to Reduce the Risk of Noncommunicable Diseases. Geneva, Switzerland: World Health Organization; 2014.

115. Guo DC, Papke CL, He R, Milewicz DM. Pathogenesis of thoracic and abdominal aortic aneurysms. Ann $N$ Y Acad Sci. 2006;1085(1):339-352. doi:10.1196/annals.1383.013

116. Al-Jarallah A, Igdoura F, Zhang Y, et al. The effect of pomegranate extract on coronary artery atherosclerosis in SR-BI/APOE double knockout mice. Atherosclerosis. 2013;228(1):80-89. doi:10.1016/j.atherosclerosis.2013.02.025

117. Xu S, Kamato D, Little PJ, Nakagawa S, Pelisek J, Jin ZG. Targeting epigenetics and non-coding RNAs in atherosclerosis: from mechanisms to therapeutics. Pharmacol Ther. 2019;196:15-43.

118. $\mathrm{Xu} \mathrm{S}$, Pelisek J, Jin ZG. Atherosclerosis is an epigenetic disease. Trends Endocrinol Metab. 2018;29(11):739-742. doi:10.1016/j. tem.2018.04.007

119. Libby P. Current concepts of the pathogenesis of the acute coronary syndromes. Circulation. 2001;104(3):365-372. doi:10.1161/01.CIR.104.3.365

120. Zingg JM, Hasan ST, Meydani M. Molecular mechanisms of hypolipidemic effects of curcumin. Biofactors. 2013;39(1):101121. doi:10.1002/biof.1072

121. Haq S, Choukroun G, Lim H, et al. Differential activation of signal transduction pathways in human hearts with hypertrophy versus advanced heart failure. Circulation. 2001;103(5):670-677. doi:10.1161/01.CIR.103.5.670 
122. Li H, Gao S, Ye J, et al. COX-2 is involved in ET-1-induced hypertrophy of neonatal rat cardiomyocytes: role of NFATc3. Mol Cell Endocrinol. 2014;382(2):998-1006. doi:10.1016/j. mce.2013.11.012

123. Nazam Ansari M, Bhandari U, Pillai K. Protective role of curcumin in myocardial oxidative damage induced by isoproterenol in rats. Hum Exp Toxicol. 2007;26(12):933-938. doi:10.1177/ 0960327107085835

124. Izem-Meziane M, Djerdjouri B, Rimbaud S, et al. Catecholamineinduced cardiac mitochondrial dysfunction and mPTP opening: protective effect of curcumin. Am J Physiol Heart Circul Physiol. 2012;302(3):H665-H674. doi:10.1152/ajpheart.00467.2011

125. Li W, Suwanwela NC, Patumraj S. Curcumin by down-regulating NF-kB and elevating Nrf2, reduces brain edema and neurological dysfunction after cerebral I/R. Microvasc Res. 2016;106:117-127. doi:10.1016/j.mvr.2015.12.008

126. Fraccarollo D, Galuppo P, Bauersachs J. Novel therapeutic approaches to post-infarction remodelling. Cardiovasc Res. 2012;94(2):293-303. doi:10.1093/cvr/cvs109

127. Tantry US, Navarese EP, Myat A, Chaudhary R, Gurbel PA. Combination oral antithrombotic therapy for the treatment of myocardial infarction: recent developments. Expert Opin Pharmacother. 2018;19(7):653-665. doi:10.1080/ 14656566.2018.1457649

128. Kalani A, Kamat PK, Kalani K, Tyagi N. Epigenetic impact of curcumin on stroke prevention. Metab Brain Dis. 2015;30 (2):427-435. doi:10.1007/s11011-014-9537-0

129. Elkordy AA, Haj-Ahmad RR, Awaad AS, Zaki RM. An overview on natural product drug formulations from conventional medicines to nanomedicines: past, present and future. J Drug Deliv Sci Technol. 2021;63:102459. doi:10.1016/j.jddst.2021.102459

130. Alissa EM, Ferns GA. Functional foods and nutraceuticals in the primary prevention of cardiovascular diseases. J Nutr Metab. 2012;2012:1-16. doi:10.1155/2012/569486

131. Zhao C-N, Meng X, Li Y, et al. Fruits for prevention and treatment of cardiovascular diseases. Nutrients. 2017;9(6):598. doi: $10.3390 /$ nu9060598

132. Thandapilly SJ, LeMaistre JL, Louis XL, Anderson CM, Netticadan T, Anderson HD. Vascular and cardiac effects of grape powder in the spontaneously hypertensive rat. $\mathrm{Am} \mathrm{J}$ Hypertens. 2012;25(10):1070-1076. doi:10.1038/ajh.2012.98

133. Terauchi M, Horiguchi N, Kajiyama A, et al. Effects of grape seed proanthocyanidin extract on menopausal symptoms, body composition, and cardiovascular parameters in middle-aged women: a randomized, double-blind, placebo-controlled pilot study. Menopause. 2014;21(9):990-996. doi:10.1097/ GME.0000000000000200

134. Cerdá B, Llorach R, Cerón JJ, Espín JC, Tomás-Barberán FA. Evaluation of the bioavailability and metabolism in the rat of punicalagin, an antioxidant polyphenol from pomegranate juice. Eur J Nutr. 2003;42(1):18-28. doi:10.1007/s00394-003-0396-4

135. Hering NA, Luettig J, Jebautzke B, Schulzke JD, Rosenthal R. The punicalagin metabolites ellagic acid and Urolithin A exert different strengthening and anti-inflammatory effects on tight junction-mediated intestinal barrier function in vitro. Front Pharmacol. 2021;12:320. doi:10.3389/fphar.2021.610164

136. Bonferoni MC, Rossi S, Sandri G, Ferrari F. Nanoparticle formulations to enhance tumor targeting of poorly soluble polyphenols with potential anticancer properties. Seminars in Cancer Biology.2017;46:205-214. doi:10.1016/j.semcancer.2017.06.010
137. Lagoa R, Silva J, Rodrigues JR, Bishayee A. Advances in phytochemical delivery systems for improved anticancer activity. Biotechnol Adv. 2020;38:107382. doi:10.1016/j. biotechadv.2019.04.004

138. Pistollato F, Bremer-Hoffmann S, Basso G, et al. Targeting glioblastoma with the use of phytocompounds and nanoparticles. Target Oncol. 2016;11(1):1-16. doi:10.1007/s11523-015-0378-5

139. Rahimi HR, Nedaeinia R, Shamloo AS, Nikdoust S, Oskuee RK. Novel delivery system for natural products: nano-curcumin formulations. Avicenna J Phytomed. 2016;6(4):383.

140. Siddiqui IA, Sanna V. Impact of nanotechnology on the delivery of natural products for cancer prevention and therapy. Mol Nutr Food Res. 2016;60(6):1330-1341. doi:10.1002/mnfr.201600035

141. Wang S, Su R, Nie S, et al. Application of nanotechnology in improving bioavailability and bioactivity of diet-derived phytochemicals. J Nutr Biochem. 2014;25(4):363-376. doi:10.1016/j. jnutbio.2013.10.002

142. Davatgaran-Taghipour Y, Masoomzadeh S, Farzaei MH, et al. Polyphenol nanoformulations for cancer therapy: experimental evidence and clinical perspective. Int $J$ Nanomedicine. 2017;12:2689. doi:10.2147/IJN.S131973

143. Pala R, Anju V, Dyavaiah M, Busi S, Nauli SM. Nanoparticlemediated drug delivery for the treatment of cardiovascular diseases. Int $J$ Nanomedicine. 2020;15:3741. doi:10.2147/IJN. S250872

144. Kuriakose D, Xiao Z. Pathophysiology and treatment of stroke: present status and future perspectives. Int $J$ Mol Sci. 2020;21 (20):7609. doi:10.3390/ijms21207609

145. Markus H. Stroke: causes and clinical features. Medicine. 2008;36(11):586-591. doi:10.1016/j.mpmed.2008.08.009

146. Libby P, Theroux P. Pathophysiology of coronary artery disease. Circulation. 2005;111(25):3481-3488. doi:10.1161/ CIRCULATIONAHA.105.537878

147. Foëx P, Sear J. Hypertension: pathophysiology and treatment. Continuing Educ Anaesth Crit Care Pain. 2004;4(3):71-75. doi:10.1093/bjaceaccp/mkh020

148. Carapetis JR, Beaton A, Cunningham MW, et al. Acute rheumatic fever and rheumatic heart disease. Nat Rev Dis Prim. 2016;2 (1): $1-24$.

149. Cunningham MW. Pathogenesis of group A streptococcal infections. Clin Microbiol Rev. 2000;13(3):470-511.

150. Kumar RK, Tandon R. Rheumatic fever \& rheumatic heart disease: the last 50 years. Indian J Med Res. 2013;137(4):643.

151. Mosterd A, Hoes AW. Clinical epidemiology of heart failure. heart. 2007;93(9):1137-1146. doi:10.1136/hrt.2003.025270

152. Pascall E, Tulloh RM. Pulmonary hypertension in congenital heart disease. Future Cardiol. 2018;14(4):343-353. doi:10.2217/ fca-2017-0065

153. Neumayer C, Fügl A, Nanobashvili J, et al. Combined enzymatic and antioxidative treatment reduces ischemia-reperfusion injury in rabbit skeletal muscle. J Surg Res. 2006;133(2):150-158. doi:10.1016/j.jss.2005.12.005

154. Nerbonne JM, Kass RS. Molecular physiology of cardiac repolarization. Physiol Rev. 2005;85(4):1205-1253. doi:10.1152/ physrev.00002.2005 


\section{Publish your work in this journal}

Vascular Health and Risk Management is an international, peerreviewed journal of therapeutics and risk management, focusing on concise rapid reporting of clinical studies on the processes involved in the maintenance of vascular health; the monitoring, prevention and treatment of vascular disease and its sequelae; and the involvement

of metabolic disorders, particularly diabetes. This journal is indexed on PubMed Central and MedLine. The manuscript management system is completely online and includes a very quick and fair peerreview system, which is all easy to use. Visit http://www.dovepress. com/testimonials.php to read real quotes from published authors.

Submit your manuscript here: https:/www.dovepress.com/vascular-health-and-risk-management-journal 